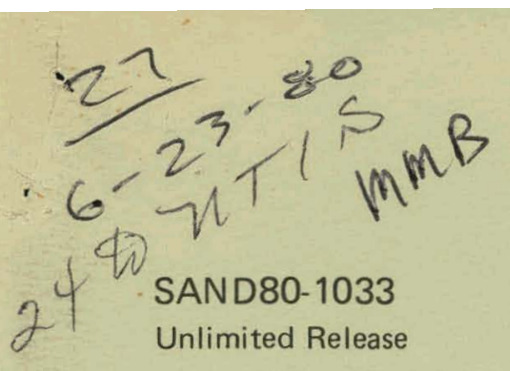

\title{
D-T Neutron Generator Development for Cancer Therapy: 1980 Annual Progress Report
}

Frank M. Bacon, Robert J. Walko, Robert W. Bickes, Jr., Donald F. Cowgill, Alfred A. Riedel, James B. O'Hagan 


\section{DISCLAIMER}

This report was prepared as an account of work sponsored by an agency of the United States Government. Neither the United States Government nor any agency Thereof, nor any of their employees, makes any warranty, express or implied, or assumes any legal liability or responsibility for the accuracy, completeness, or usefulness of any information, apparatus, product, or process disclosed, or represents that its use would not infringe privately owned rights. Reference herein to any specific commercial product, process, or service by trade name, trademark, manufacturer, or otherwise does not necessarily constitute or imply its endorsement, recommendation, or favoring by the United States Government or any agency thereof. The views and opinions of authors expressed herein do not necessarily state or reflect those of the United States Government or any agency thereof. 


\section{DISCLAIMER}

Portions of this document may be illegible in electronic image products. Images are produced from the best available original document. 
Issued by Sandia Laboratories, operated for the United States Department of Energy by Sandia Corporation.

\section{NOTICE}

This report was prepared as an account of work sponsored by the United States Government. Neither the United States nor the Department of Energy, nor any of their employees, nor any of their contractors, subcontractors, or thelr employees, makes any warranty, express or implied, or assumes any legal liability or responsibility for the accuidicy, cumpleleıtess or usefulness of any liffumatiun, anpaiatus, product or process disclosed, or represents that its use would not infringe privately owned rights.

Printed in the United States of America.

Available from

National Technical Information Service

U.S. Department of Commerce

5285 Port Royal Road

springfield, VA 22161

Prince: Prined Copy $\$ 4.50$ : Microfiche $\$ 3.00$ 
SAND80- 1033

Unlimited Release

Printed May 1980

D-T NEUTRON GENERATOR DEVELOPMENT FOR CANCER THERAPY: 1980 ANNUAL PROGRESS REPORT

\author{
Frank M. Bacon \\ Robert J. Walko \\ Robert W. Bickes, Jr., \\ Donald F. Cowgill \\ Aifred A. Riedel \\ James B. O'Hagan \\ Applied Technology Division 2352 \\ Sandia National Laboratories \\ Albuquerque, New Meixco 87185
}

\begin{abstract}
This report summarizes the work completed during the first year of a two-year grant by NCI/HEW to investigate the feasibility of developing a D-T neutron generator for use in cancer therapy: Experiments have continued on the Target Test Facility (TTF) developed during a previous grant to investigate high-temperature metal hydrides for use as target materials. The high voltage reliability of the TTF has been improved so that $200 \mathrm{kV}, 200 \mathrm{~mA}$ operation is now routine. In recent target tests, the $D-D$ neutron production rate was measured to be $>1 \times 10^{11} / \mathrm{s}$, a rate that corresponds to a D-T neutron production rate of $>1 \times 10^{13} / \mathrm{s}$ - the desired rate for use in cancer therapy. Deuterium concentration depth profiles in the target, measured during intense ion beam bombardment, show that deuterium is depleted near the surface of the target due to impurities implanted by the ion beam. Recent modifications of the duopigatron ion source to reduce secondary electron damage to the electrodes also improved the ion source efficiency by about $40 \%$. An ultra high vacuum version of the TTF is now being constructed to determine if improved vacuum conditions will reduce ion source impurities to a sufficiently low level that the deuterium near the surface of the target is not depeleted. Testing will hegin in June, 1980.
\end{abstract}




\section{FOREWORD}

This work is sponsored by the Natfund Cancer Institute under HFW firant No. CA25156-01. The project is centered in the Applied Technology Division of the Neutron Devices and Technology Department of Sandia National Laboratories, Albuquerque, with Frank M. Bacon as principal investigator. Project Officer for NCI is Francis J. Mahoney. The two year grant was initiated on June 4, 1979; authorization from DOE to Sandia was received on July 13, 1979. 


\section{INTRODUCTION}

The primary objective of the present grant is the development of a neutron generator based on the $D(t, n)^{4} \mathrm{He}$ reaction (commonly called a $D-T$ neutron generator) for use in cancer therapy. The generator will consist of a $200 \mathrm{kV}$ ion accelerator capable of delivering a $200 \mathrm{~mA}$ deuterium and tritium ion beam, produced in an ion source, to a solid target containing deuterium and tritium. The target consists of a high-temperature, metal hydride film on a water-cooled metal substrate.1,2 Although the system will be designed to handle tritium, only deuterium will be used in the tests because radiation hazards are considerably reduced. Tritium operation will be possible after a neutron shield is designed and constructed under a future grant. The goal for neutron production rate from the $D(d, n)^{3}$ He reaction is $10^{11} / \mathrm{s}$ which scales to $10^{13} / \mathrm{s}$ from the $D-T$ reaction, the desired rate for use in cancer therapy.

In a previous research program, a target was developed for use in an intense neutron source. ${ }^{1,2}$ Experiments performed on a deuterium ion accelerator called the Target Test Facility (TTF) showed that the neutron output and target lifetime were detrimentally affected by impurities in the ion beam. Modified ion source electrodes ${ }^{3}$ and an ultra-high-vacuum (UHV) accelerator were proposed ${ }^{4}$ as solutions to the impurity problems. High-voltage reliability was demonstrated to be inadequate on the TTF and steps have been taken to improve the high voltage characteristics of the accelerator and the high voltage power supply. In parallel with the design and construction of the UHV accelerator, target experiments on the TTF have continued and now include the capability of monitoring the deuterium concentration depth profile $e^{5}$ in the target during ion beam bombardment. Ion source experiments have included further work on the duopigatron ${ }^{6}$, the ion source used on the TTF, and the design and construction of a multi-cusp magnetic field ion source. The latter ion source has the possible potential of operating at sufficiently low pressure that a non-pumped neutron tube could be designed; this feature would_simplify tube operation and reduce the tritium inventory.

\section{TTF EXPERIMENTS}

\section{A. TTF Modification.}

A target analysis chamber has been added to the TTF to allow deuterium concentration depth profile measurements to be made as described in the next section. A schematic diagram of the TTF assembly is shown in Fig. 1. The target is now located $1.5 \mathrm{~m}$ from the ion source compared to $0.6 \mathrm{~m}$ in the earlier version of the TTF. To transport the beam the additional distance while maintaining a beam diameter at the target of $35 \mathrm{~mm}$, the beam neutralization point was moved closer to the accelerator gap as described previously.1,2 In the initial experiments with the longer source-to-target spacing, 


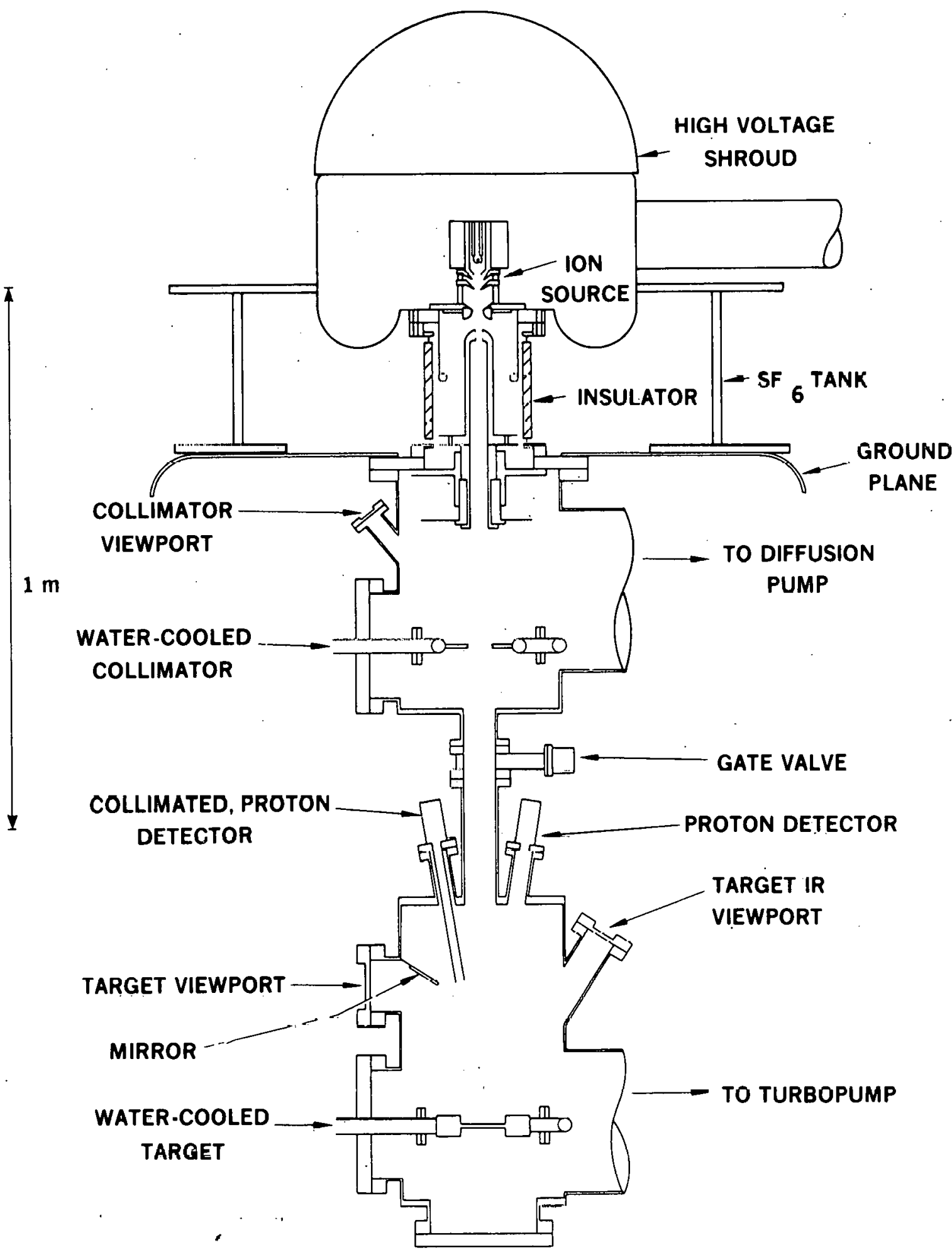

Fig. I. Schematic drawing of Target lest Facillty. 
the beam diameter was larger than anticipated assuming a space-charge-neutralized ion beam. The gas pressure in the lower chamber was about 10-5 Torr. Adding argon or hydrogen gas to the lower chamber reduced the ion beam diameter and increased the peak surface temperature of the target due to ion beam heating, as measured using the infra-red camera. ${ }^{1,2} \mathrm{~A}$ plot of the peak surface temperature of the target due to beam heating as a function of hydrogen pressure in the lower chamber is shown in Fig. 2

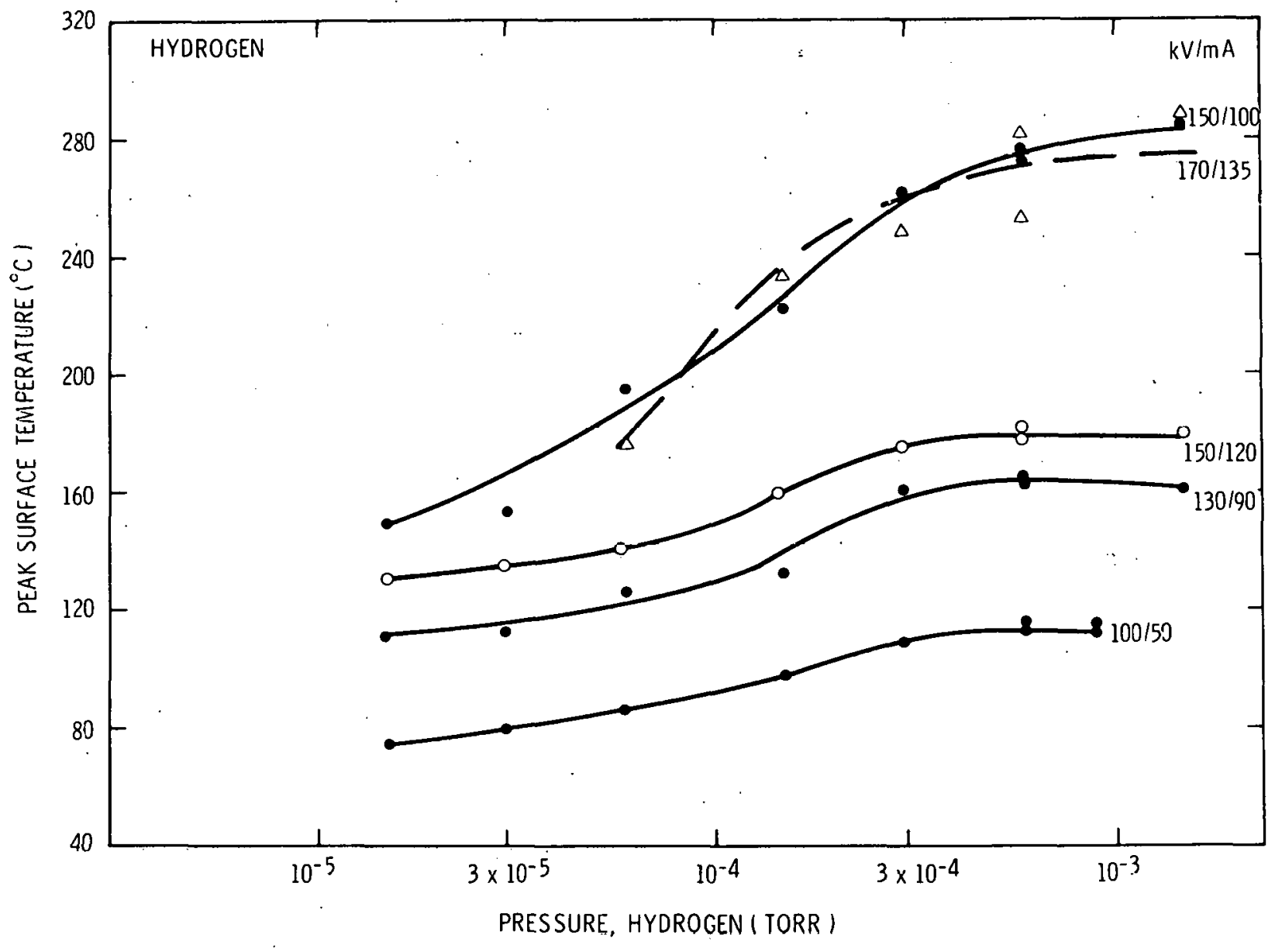

Fig. 2. Peak surface temperature of target due to ion beam heating versus hydrogen pressure in lower chamber of TTF. Several curves are shown for different operating conditions.

for several operating conditions. These data indicate the hydrogen pressure should be above $3 \times 10^{-4}$ Torr to provide sufficient electrons from ionization of the background gas for space charge neutralization of the ion beam. Similar data for argon backfill showed that the argon pressure had to be greater than $1 \times 10^{-4}$ Torr. The difference in pressure requirements for hydrogen and argon is presumably due to the smaller electron producing cross sections for hydrogen compared to argon?. 
Instrumentation on the new target chamber (lower chamber in Fig. 1) includes the proportional counter proton detector for measuring the neutron output and the IR camera to measure the target radiance due to ion beam heating as described previous $1 y, 1,2$. In addition, collimated proton detectors have been mounted on the chamber to view small areas on the target; these detectors are used in the deuterium concentration depth profile measurements described in the next section.

\section{B. Deuterium Concentration Depth Profile Measurements/Beam Impurity Effects}

An intense neutron source suitable for cancer therapy must possess a stable longlived output. During the past year, three fully-loaded $\mathrm{SCD}_{2}$ targets have been run on the TTF under $150 \mathrm{keV}, 120 \mathrm{~mA}$ deuteron bombardment. Each exhibited a neutron output characterized by a rapid decay for the first 200 minutes of operation, followed by a slower decay, leveling off at about $50 \%$ of the initial value. This decay, for the experimental run with the most stable beam, is described by the whole target curve shown in Fig. 3.

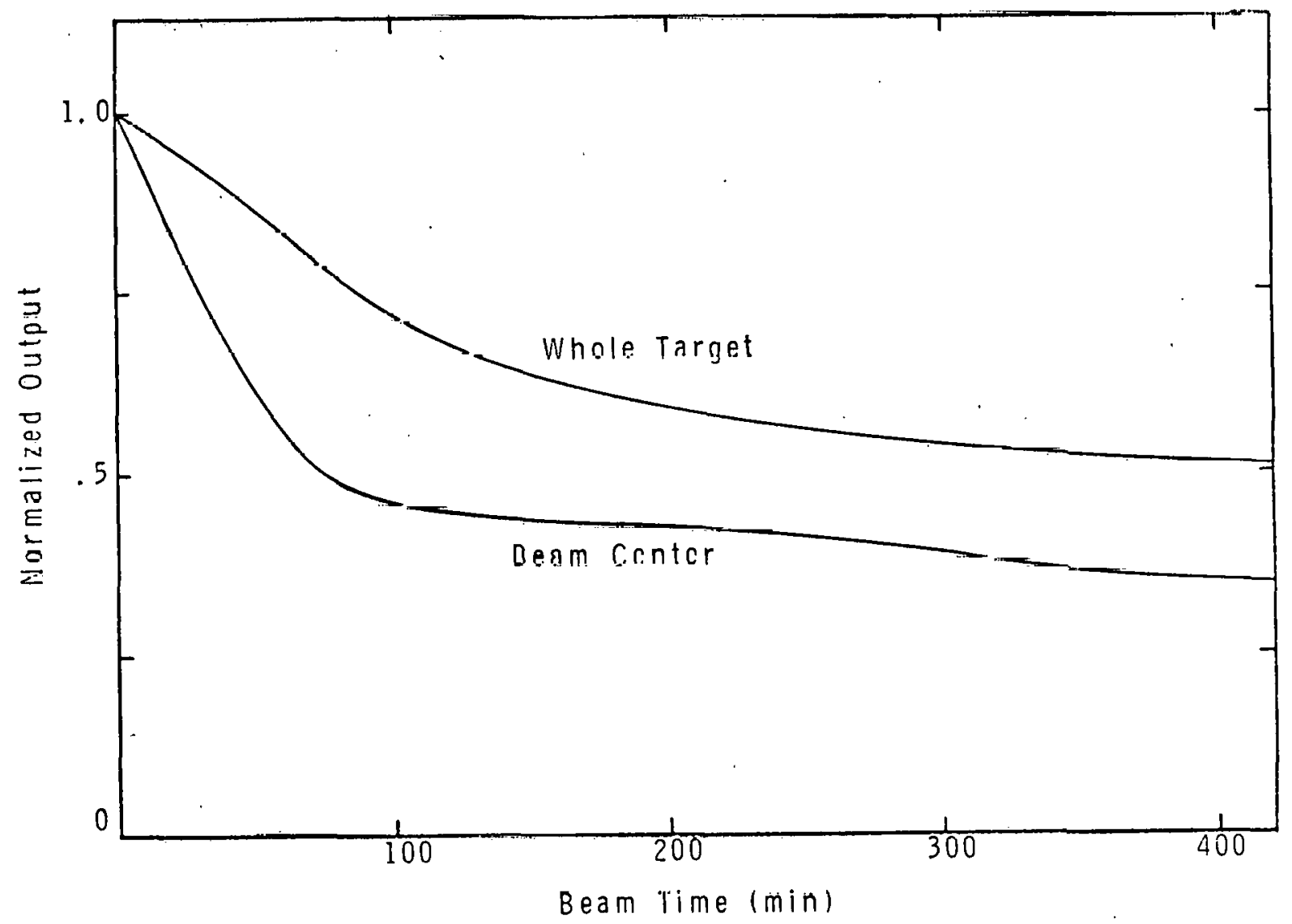

Fig. 3. Neutron output decay observed for $150 \mathrm{keV}, 120 \mathrm{~mA}$ bombardment of $\mathrm{ScD}_{2}$. The output produced by the highest current density portion of the beam (center) decayed more rapidly than the whole target average. 
It was deduced from the proton output of the $D(d, p) T$ reaction, as measured by a proportional counter. The output produced by the center $20 \%$ of the beam current was also measured for this target. Here a surface barrier detector and several collimating apertures were used to observe only the protons produced by the center $0.5 \mathrm{~cm} \mathrm{dia}$. of the beam. This output was found to decay more rapidly than that of the whole target, as shown in Fig. 3. The more rapid decay is assumed to be associated with the higher current density present at the center of the beam. This report summzarizes present investigations into the origins of this decaying output. Depth-dependent, dynamic profiles of the deuterium concentration and post-morten target analyses indicate the observed decay is due to impurity-produced deuterium desorption.

In order to understand the decaying output, depth profiles of the deuterium concentration were deduced for the center beam spot area profiles of the deuterium bombardment. These were obtained by analyzing the energy spectra of protons detected with the surface barrier detector, according to the procedure developed in Ref. 8. The detection geometry used is described by the parameters: $\phi=165^{\circ}$ (relative to the beam direction), $\Omega=3.49 \times 10^{-5} \mathrm{sr}$, observed target area $=19.3 \mathrm{~mm}^{2}$, Al foil detector filter thickness $=2 \mu \mathrm{m}$. The initial spectrum obtained from a $\mathrm{ScD}_{2} \operatorname{target}$ for the first 2 minutes of operation is shown in Fig. 4. This target was analyzed prior to the TTF bombardment using the nuclear reaction technique at low curront density and determined to have a deuterium-to-metal ratio of $\mathrm{D} / \mathrm{SC}=1.95 \pm .05$. This spectrum was used as a "standard" to provide normalization for the profile reduction.

Spectrum analysis on the TTF is complicated by the fact that the ion beam is composed $\mathrm{D}^{+}, \mathrm{D}_{2}^{+}$, and $\mathrm{D}_{3}^{+}$ions. As a result, the proton spectrum is a superposition of the spectra produced by the three ions. The procedure for reducing a deuteronproduced spectrum into a target deuterium depth profile has been shown to be accurate to a depth of about $0.9 \mu \mathrm{m}$ for $200 \mathrm{keV}$ deuterons on $\mathrm{ScD}_{2} \cdot{ }^{8}$ Subsequent measurements have found that this profiling range is reduced to about $0.6 \mu \mathrm{m}$ for $150 \mathrm{keV}$ deuterons. For the back-reaction geometries $(\phi>\pi / 2)$, the enerq. of an emitted proton increases with decreasing deuteron energy. Thus, proton energies increase with reaction depth in the target. Only a small amount of this energy increase with depth is lost as the proton escapes the target. The spectrum produced by the $\mathrm{D}_{2}{ }^{+}$ions may be obtained by treating a $\mathrm{D}_{2}^{+}$ion as two deuterons, each with half the energy of the beam. Since these deuteron energies are lower, this spectrum occurs higher in energy than that produced by the $D^{+}$ ions. A similar situation results for the $\mathrm{D}_{3}{ }^{+}$. ions. Figure 5 shows the projected depths corresponding to the energies of the detected protons for each beam component. Clearly, the lowest energy protons resulted from the $D^{+}$ions alone. As a result this region can be analyzed in a straightforward manner to give a deuterium profile to a depth of about $0.4 \mu \mathrm{m}$. Using the "standard" spectrum, such an analysis requires antique value for the $D^{+}$fluence. The region of proton energies $2.73 \leq \mathrm{E}_{\mathrm{p}}<2.78 \mathrm{MeV}$ is a superposition arising from protons produced at depths $<4 \mu \mathrm{m}$ by $\mathrm{D}^{+}$ions and protons produced near the surface $\left(x_{\mathrm{p}}<0.2 \mu \mathrm{m}\right)$ by 


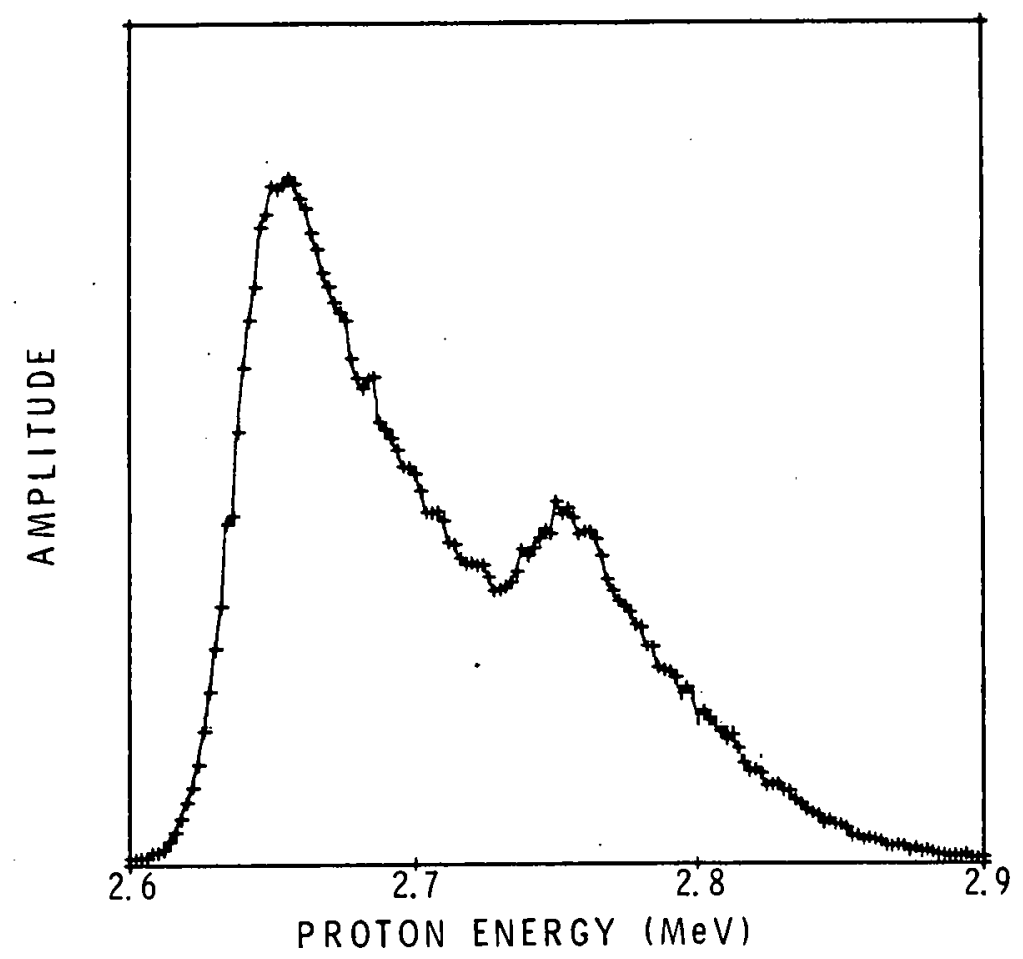

Fig. 4. Proton energy spectrum from a fully-loaded $\mathrm{SCD}_{2}$ target during the first 3 minutes of bombardment. The smaller peak results from $\mathrm{D}_{2}^{+}$ions in the beam. A third, low amplitude, unresolved higher energy peak produced by the $\mathrm{D}_{3}{ }^{+}$ions also resides on the high energy tail of the $D^{+}$peak.

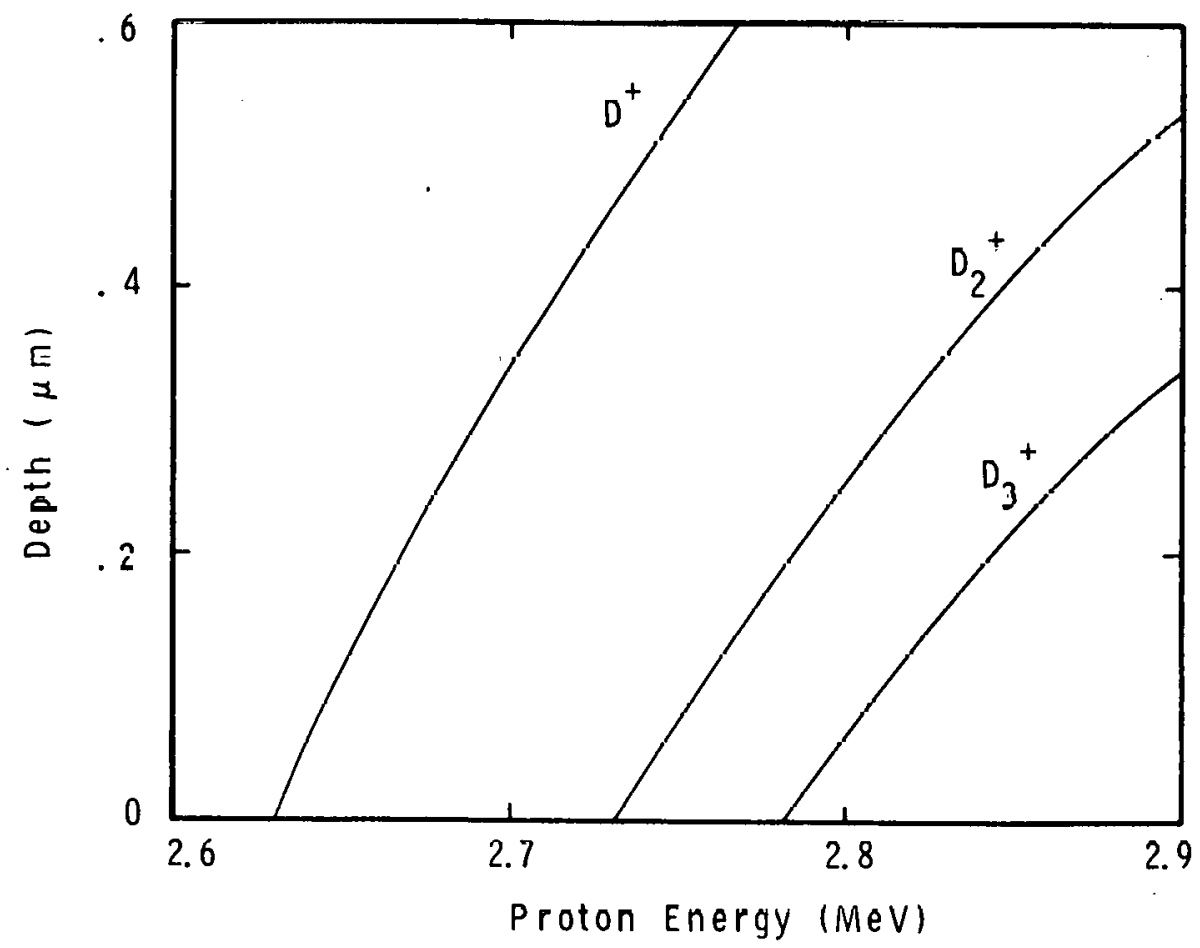

Fig. 5. Projected depths corresponding to the detected energies of protons produced by the three beam components. Spectral overlap occurs only for proton energies above $2.73 \mathrm{MeV}$. 
$\mathrm{D}_{2}{ }^{+}$ions. These may be separated by requiring profiles deduced from each component to agree with the standard. Compensation must also be made for resolution produced broadening of surface proton addresses. This procedure uniquely determines the only adjustable parameter, the $\mathrm{D}_{2}^{+}$. fluence for the spectrum. The spectrum and its components for the protons used in deducing the profile to a depth of $0.6 \mu \mathrm{m}$ are shown in Fig. 6 .

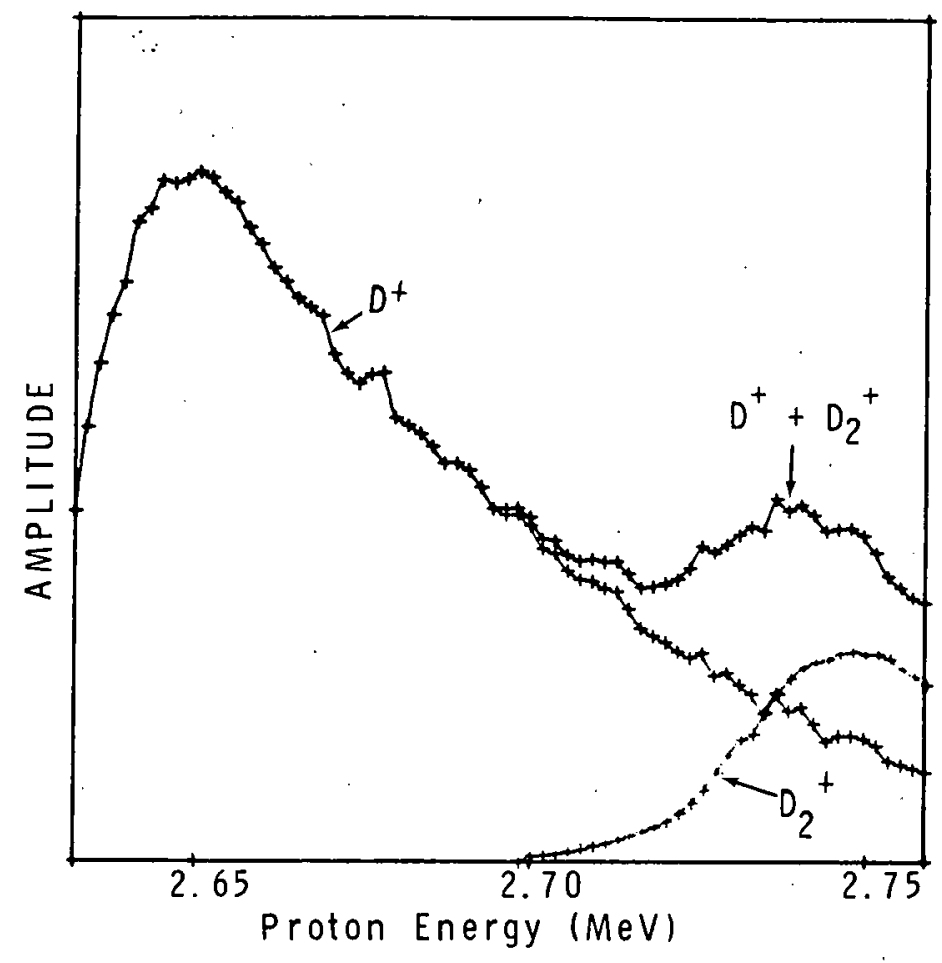

Fig. 6. Separation of the spectrum components produced by $\mathrm{D}^{+}$and $\mathrm{D}_{2}^{+}$ions. Deuterium depth profiles are deduced from the $D^{+}$component.

Only the $\mathrm{D}^{+}$and $\mathrm{D}_{2}^{+}$components are required for this analysis. The beam composition, determined with an accuracy of about. $5 \%$ by this procedure, was $\mathrm{D}^{+}: \mathrm{D}_{2}^{+}: \mathrm{D}_{3}{ }^{+}=55: 36: 9$, in close agreement with ion beam analysis. ${ }^{6}$

Sixteen spectra were obtained during about 7 hours of target bombardment. Except for the first, all were accumulated for a duration of 10 minutes in order to obtain good statistics. The profiles deduced for the average beam times of $2,12,36,56.77$, 183, and 420 minutes are shown in Fig. 7. The uutput decay of Fig. 1 is clearly the result of a depletion of deuterium within the top fraction of a micron of the larget film. This cannot be due to overheating of the target, since such a condition would produce profiles uniformly depleted in depth, due to high deuterium diffusion. In addition, a low current density deuteron beam was found unable to reload this film. 
The rapid depletion for the top $0.2 \mu \mathrm{m}$ of the target suggest an impurity produced desorption mechanism. Indeed the range of $150 \mathrm{keV}$, low $Z$ impurities in Sc and its low 7 compunds is about $0.2 \mu \mathrm{m}$. Following the experimental run, the ceriter of this target was analyzed for low $Z$ impurities using nuclear reaction techniques at $1.4 \mathrm{MeV}$. The results of this analys is are summarized in Table I. A total of about $1.9 \times 10^{18}$ atoms $/ \mathrm{cm}^{2}$ were found of $0, C$, and $\mathrm{N}$ impurities. Scandium forms stable compounds with each of these impurities, the most probable of which are tabulated. Assuming that each impurity atom resides in one of these compounds implies that the deuterium is detrapped at the indicated D/Impurity ratio. The net result is that a total of about $3.1 \times 10^{18} \mathrm{D} / \mathrm{cm}^{2}$ would be released from the scandium and free to escape the target film. Integrating the difference between the 2 and 420 minute profiles of Fig. 5 and using a Sc atom density of $3.6 \times 10^{22} \mathrm{cmll}^{-3}$ produces a deuterium depletion of $2.9 \times 1018 \mathrm{~m} / \mathrm{r} \cdot \mathrm{m}^{2}$. Thus the utserved sutput decay is believed to be understood in terms of beam implanted impurities, The tllilial rapid deray results from deuterium detrapping in the implanted layer. The subsequent slower decay results from a migration of the impurities to deeper depths within the film. Deuterium prufiles obtained for even longer bombardment times on other experimental runs agree well with the 420 minute profile of Fig. 7. Thus the impurities in the target appear to reach a saturation level.

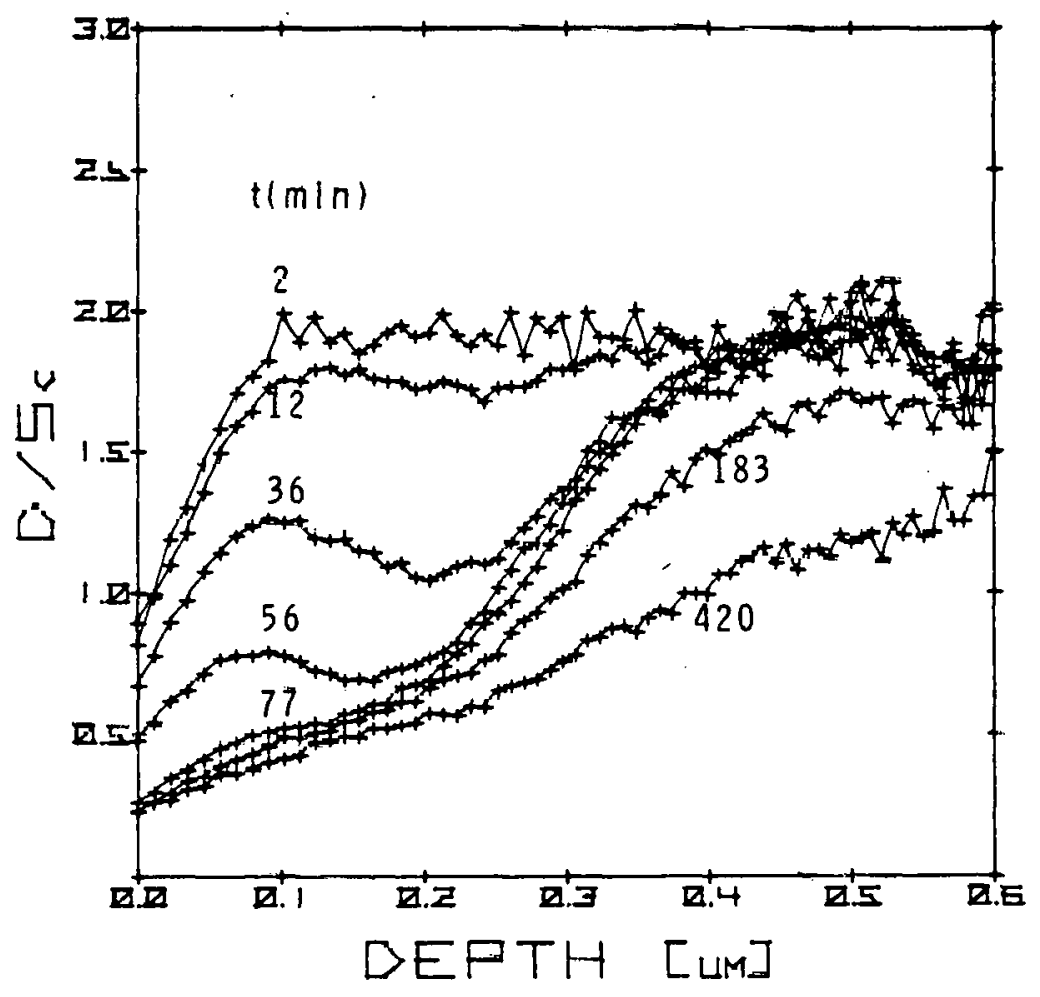

Fig. 7. Deuterium profiles obtained as a function of beam time. Deuterium is first depleted from the surface region, then from deeper withill the target film. 
Table I. Post Mortem Target Analysis using Nuclear Reaction Analysis.

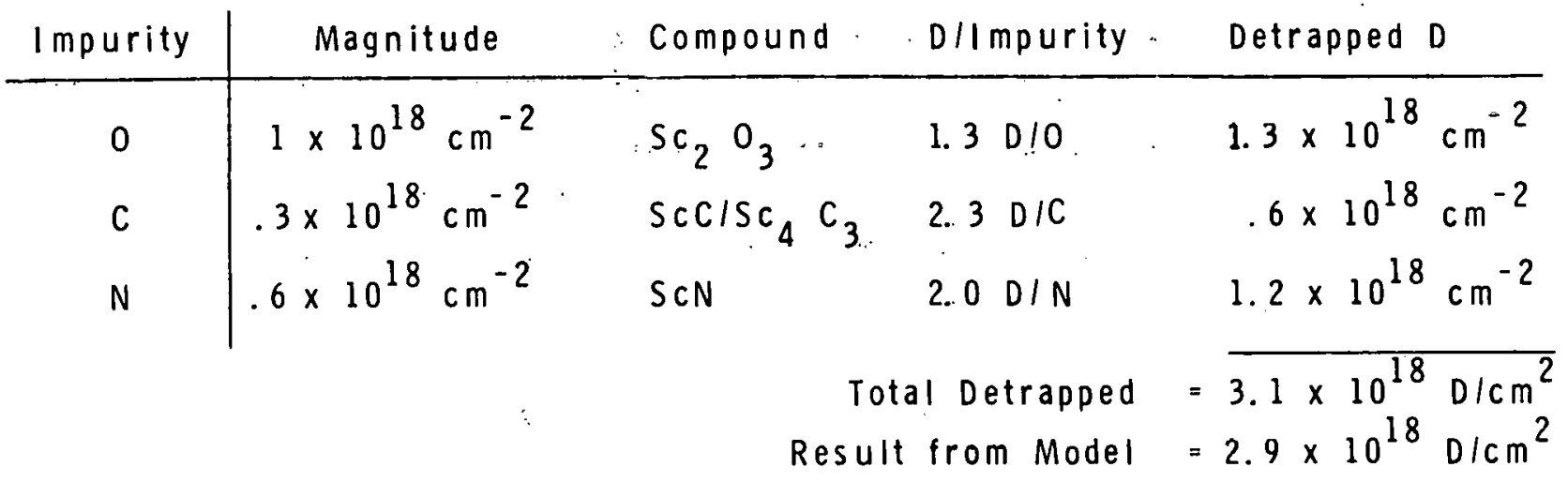

The initial rate at which the depletion proceeds can be used to determine the impurity levels in the beam. Figure 8 shows the integrated deuterium loss deduced from the dynamic profiles as a function of total beam fluence. The initial detrapping rate shown by the dotted line is $0.0086 \mathrm{D} / \mathrm{ion}$. If the impurity proportions in the beam are the same as those found by the post-mortem analysis, this detrapping rate corresponds to a total beaili impurity level of about $0.5 \%$, in good agreement with the beam analysis of Bickes and 0 'Hagan: ${ }^{3}$ This impurity-implant detrapping mechanism is being modeled to include the effects of surface sputtering and impurity diffusion. The net effect for an intense neutron source is to reduce the output to about $50 \%$ after the impurity saturation level is reached. Reducing the impurity level in the beam should extend the time before this reduced, stable operation is achieved. Other target film materials will be investigated for their impurity implant, and diffusion behavior.

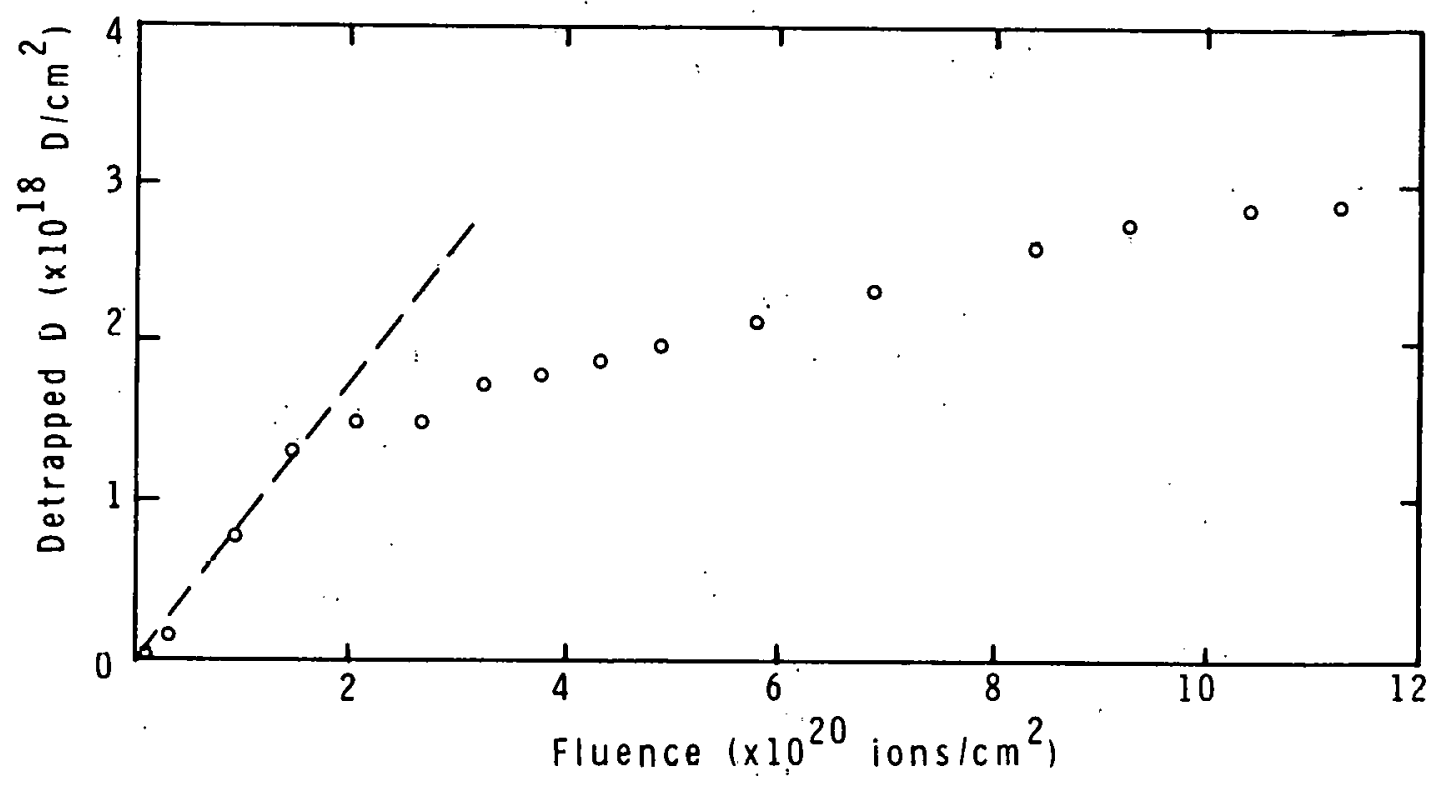

Fig. 8. Integrated deuterium loss as a function of beam fluence. The initial detrapping rate is constant and gives a measure of the beam impurity concentration. 
Experiments on a $50 \mu \mathrm{m}$ thick scandium target film are in process at this time. These tests were made to verify that the beam power density of $q \mathrm{~kW} / \mathrm{cm}^{2}$ could be conducted through the thicker film; previous work has been done on film thicknesses up to $10 \mu \mathrm{m}$. Initial tests at $200 \mathrm{kV}, 200 \mathrm{~mA}$ with a beall spot size of about $10 \mathrm{~cm}^{2}$ showed that the power density could be dissipated with no apparent difference between the $10 \mu \mathrm{m}$ and $50 \mu \mathrm{m}$ thick films. The D-D neutron output rate was $(1.1-1.9)$ $\times 10^{11} / \mathrm{s}$ which scales to a D-T neutron output rate of $1-2 \times 10^{13} / \mathrm{s}$. The tests will be continued to analyze the deuterium depth profiles and to determine the long-term neutron output rate similar to the work reported above.

\section{c. Accelerator Modifications for Better Reliability and Stability}

Several modifications have been made to the prosent TTF to improve its performance. first, lie IIV power supply was modified to Impruve its high voltage operation. Prior to the modifications, sparks in the dccelerator would initiate a high-voltage breakdown, (HVB) inside the power-supply. Following several conversations with Universal Voltronics, new transformer windings were purchased that had improved flashover characteristics. since installation of these windings, breakdowns due to internal flashover of the power supply have not been observed.

Second, the high voltage feedthrough which provides the secondary electron suppression bias to the extractor electrode was changed to one having a higher voltage rating. In addition, its in-vacuum lead was covered with a single piecc of glass tubing to prevent HVB's by shielding the bias lead from the plasma present in the neutralizing region. This was done to permit experiments with higher bias potentials to determine their effect on ion source operation. Before the mudification, the bias was limited by HVR's to $4 \mathrm{kV}$. Now, bias potentials at least as high as $10 \mathrm{kV}$ are possible without HVB's. A preliminary result indicates that $7 \mathrm{kV}$ bias will be required for reliable 200 K.V speration.

The third modification involved a re-design of the extractor-neutralizer mounting assembly to provide a more rigid structure. Ihis change was prompted by the observation that the ion beam was moving on the larget in respunse to the application of high accelerating voltages. Some movement of the electrnde structure was detectable by hand pressures, and it was theorized that the electrodes were being shifted by electrostatic forros. Since the modification, only small slowly changing deflections have been observed, and these are probably due to thermal effecls.

Fourth, the molybdenuril extractor cap was mindified to assure that it would remain rigidly attached to the extractor electrode. This was done after it was discovered that the electrostatic fields could dislodye the cap after it hecame heated, thereby inducing breakdown, or even skewing the ion beam to the extent that it could damage parts of the vacuum chamber. This modification has eliminated that problem. 
Fifth, the ion source configuration has been modified to improve its operation. The aperture in the intermediate electrode, anode and secondary cathode were increased from $6.4 \mathrm{~mm}$ to $9.5 \mathrm{~mm}, 9.5 \mathrm{~mm}$ and $12.7 \mathrm{~mm}$, respectively. As discussed in Section III, the modification dramatically improved the source's extraction efficiency. Boron nitride insulator sleeves have replaced the alumina sleeves on the filament holder posts in the ion source. Unlike alumina, boron nitride is not as susceptible to cracking and shattering when bombarded by the secondary electron beam, and thus far no problems have been encountered with its use. A secondary electron beam catcher was fabricated to absorb the high energy of secondary electrons, which are focused back into the ion source, without melting. The catcher consists of a $4.8 \mathrm{~mm}$ concentric conical hole drilled into the solid, water cooled copper filament holder mounted at the top of the ion source. No melting or other damage to the catcher has been observed with adequate bias at $200 \mathrm{kV}$ even after several hours of operation. In a similar manner, a copper disk was brazed over the snout of the intermediate electrode to improve its thermal conductivity thereby el iminating secondary electron damage to the intermediate electrode aperture region. To improve the beam focus, a new focus electrode was fabricated which, according to computer simulations by J. E. Boers, ${ }^{9}$ should provide a more highly focused beam. Preliminary results tend to support that prediction although additional testing is necessary.

Sixth, an ion source pulser has been constructed and installed in series with the ion source arc supply. It has been found that by pulsing the ion source off for 1 second when triggered by corona or pre-breakdown electrical noise, HVB's internal to the tube can be virtually eliminated. It is believed that such HVB's are aggravated by the presence of the ion beam, and by turning off the source for 1 second, the HVB's are not initiated. It is anticipated that such a source pulsing scheme will be incorporated into the final tube design.

Seventh, it has recently been found that optimum focusing can be achieved with the present ion source by proper adjustment of the magnitude of the magnetic field. The focus can be so improved that the heating of ancillary parts of the vacuum system close to the beam is drasticaliy reduced. Therefore, a remote adjustment to the magnet current power supply has been installed to permit fine tuning of the beam focus from the control console.

Eighth, the ability of the magnetic field to affect beam focus has been exploited to prevent beam overfucusing. By using the output of the ion source pulser mentioned earlier to simultaneously trigger the magnet it is possible to defocus the beam during source restart. This prevents the beam from passing through the overfocus mode thereby preventing target damage from overheating. 
Ninth, an INFICON mass spectrometer has been installed on the accelerator side of the vacuum chamber. This addition has greatly improved the vacuum reproducibility and reliability by helping to track down permeation and other small leaks which may have been responsible for variability in earlier results. It has also provided a simple means of determing the proper filament activation procedure by displaying its characteristic outgassing spectrum.

Tenth, filters have been installed in the chilled water lines which provide cooling for the target. Since the filters were installed, reductions in water flow due to plugging of the target cooling channels has not been observed.

Finally, dispenser type cathodes, possible replacements for dipped type filaments, have been tested. The dispenser cathodes, obtained from Spectra Mat. Inc., have been found to perform as well as the dipped filaments, with the possible added benefit of fewer HVB'E during operations. Stnce lie dispenser cathodes produce no powdery residue from activiation (in contrast to the dipped filaments) it is now belleved that many breakdowns may have resulted from particles falling into the high voltage gap. The only disadvantages of the dispenser cathodes have been a variability in their activation characteristics when new, a slight difficulty in reactivation after an air exposure, and a tendency to sag after several hours of operation.

As a result of the above modifications, operation with an ion beam current of 180 to $205 \mathrm{~mA}$ at $200 \mathrm{kV}$ has been achieved. At the time of this writing, the integrated operating time at this level without an HVB is over 5 hours, and it appears that such opcration shnuld be virtually unlimited by either the ion source or accelerator.

\section{ION SOURCE EXPERIMENTS}

\section{A. Duopigatron}

Difficulties with the operation of the duoplyaliun ion source have heen encountered during TTF experiments. The problems observed included filament contamination (indicated by a satiny hlark coating after operation), failure of the source to re-start after a high voltage breakdown (HVB), reduced ion source efficiency (low lon curpenls for a given arc current), and damage to the source electrodes by secondary electrons streaming back from the accelerating region of the TTF into the ion source. An extensive series of expertments using the iun source test stand and a new mass spectrometer test stand were carried out in order to isolate each of the difficulties and to search for procedures or changes to eliminate the problems.

Scanning Auger surface analysis of the black coating on the filaments determined that the film was carbon with a trace amount of sulfur. Operating the ion source (and the filament) with a gas feed containing a few percent of air did not blacken the filament; however, operation in a gas feed containing $\mathrm{CO}_{2}$ re-produced the satiny 
black coating. This latter result substantiated the hypothesis that the free carbon contamination was generated by the reduction on the Pt surface of $\mathrm{CO}_{2}$ eluded during activation of the oxide filament. Further experimentation showed that the blackening could be minimized by activating the filaments to higher temperatures. In particular, the oxide filaments should be activated to 28A instead of the previously used 24A to completely remove $\mathrm{CO}_{2}$.

In addition to the carbon coating on the filaments, there were areas that were discolored a "mud brown" color. The exact source of this discoloration is not known but it has been determined that it is caused by the intermediate electrode (IE). Also, this discoloration and/or the carbon coating often lead to deactivation of the filament and the ion source would then not re-start after an HVB or a shut down. In order to minimize the filament deactivation and discoloration, it was found best to activate the filaments outside of the ion source. Prevention of filament contamination minimizes the source re-start difficulties.

The loss in ion source efficiency has proven to be a very complex problem. The cause of the difficulty is in the intermediate electrode/filament assembly. This was determined by systematically interchanging the source components (i.e., IE, anode, cathode holder, secondary cathode and ceramic spacers, see Fig. 9). Certain "contaminated" IE's reduced the ion current by more than $40 \mathrm{~mA}$ for a given arc current. For example, at an arc current of $20 \mathrm{~A}$ a good IE produced an ion current of $163 \mathrm{~mA}$ compared with a bad IE that yielded a current of $111 \mathrm{~mA}$. The source of the contaminates is believed to be due in part to the activation of the filaments inside the IE. Hence external activation has a two-fold purpose, the minimization of both filament and IE contamination. In addition, there appears to be a slight reduction in efficiency if a Mo cap is brazed to the tip of the IE. However, the need to prevent damage to the IE may require the use of the Mo piece.

In order to minimize electrode damage due to secondary electrons streaming back from the accelerating region of the TTF into the ion source, larger electrode apertures were required. Therefore, the ion source performance characteristics consisting of total ion current, ion energy and mass distribution, and ion current density distributions were measured as a function of the aperture size of the IE, anode and secondary cathode. The experimental techniques employed were the same as those previously described $6,10,11$ and in particular the source described as Mode 5 in Ref. 6 was used as the basis for comparison. In addition, measurements were made for both Mo and BN secondary cathodes. 


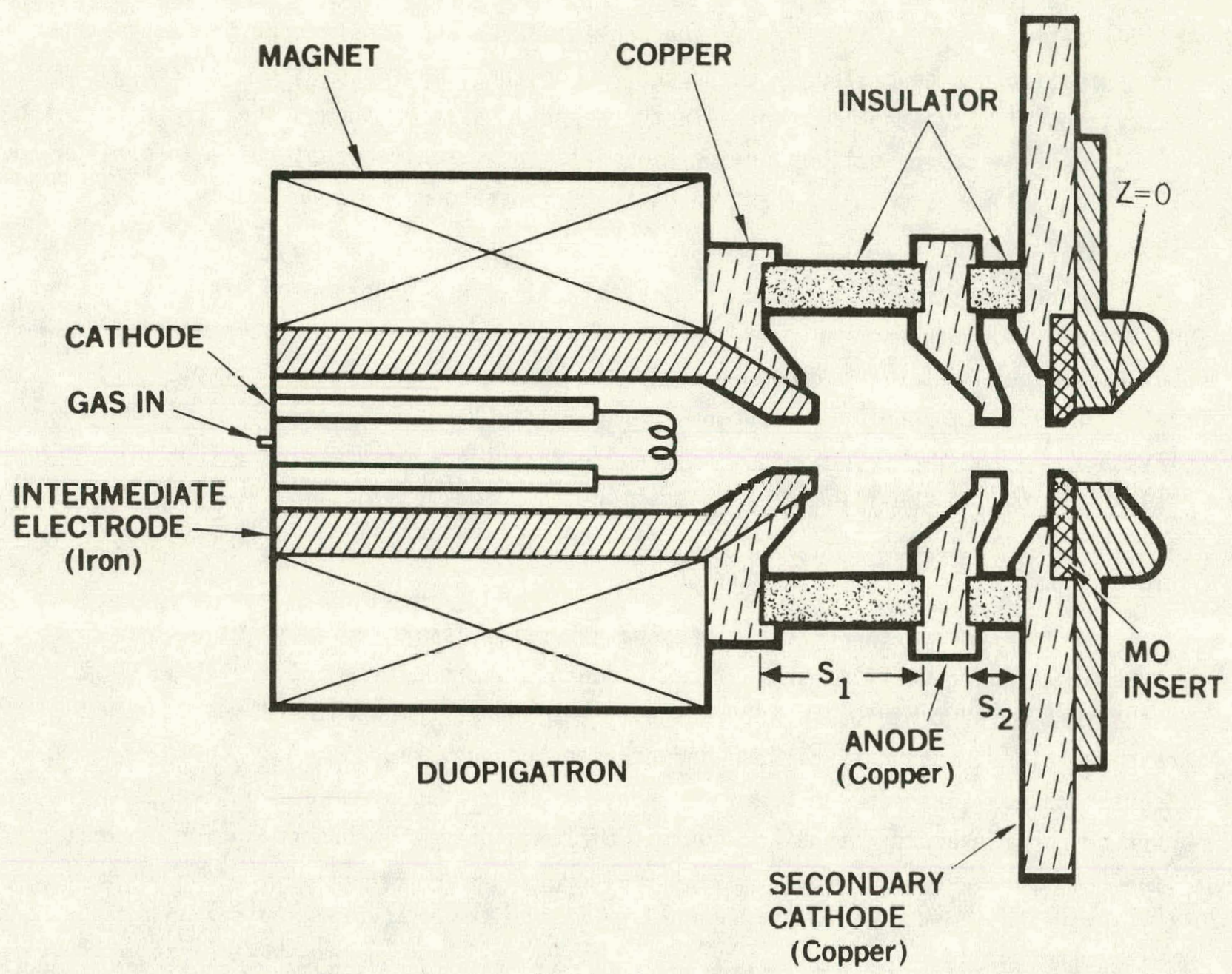

Fig. 9. Schematic Drawing of the Duopigatron Ion Source.

In order to simplify the description of the source configurations, the original (sma11) aperture diameters are designated "S" and the Mode1 5 source becomes SSS to indicate an IE diameter of $6.4 \mathrm{~mm}$ an anode diameter of $7.1 \mathrm{~mm}$ and a secondary cathode diameter of $7.1 \mathrm{~mm}$. Apertures of $9.5 \mathrm{~mm}$ are designated "I" and the $12.7 \mathrm{~mm}$ apertures, "L". A source with a $6.4 \mathrm{~mm} \mathrm{IE,} \mathrm{a} 9.5 \mathrm{~mm}$ anode and a $12.7 \mathrm{~mm}$ secondary cathode becomes SIL. A summary of the operating conditions required to produce a $200 \mathrm{~mA}$ beam is given in Table II. With the exception of two configurations, a $200 \mathrm{~mA}$ beam could be produced using arc currents less than 20A and at gas flow rates compatible with the TTF pumping speed. In addition, a BN secondary cathode is seen to yield a more efficient source operating at ca. twenty percent less power than the corresponding sources with a Mo secondary cathode. The peak in the energy distributions for all three deuterium ion constituents occurred approximately $15 \mathrm{~V}$ below anode potential (see Fig. 10 for a comparison of two representative configurations). 
Table II. Summary of Experimental Data Obtained on Duopigatron Designs with Various Electrode Apertures

\begin{tabular}{|c|c|c|c|c|c|c|c|}
\hline Configuration* & $P_{S}(P a)$ & $\mathrm{F}(\mathrm{sccm})$ & $V_{A}(V)$ & $\mathrm{I}_{A}(A)$ & $\begin{array}{l}\text { Secondary } \\
\text { Cathode }\end{array}$ & $I^{+}(m A)$ & $D^{+}(\%)$ \\
\hline SSS & 9.3 & 11.5 & 85 & 20.0 & Mo & 177 & 55 \\
\hline SSS & 9.3 & 12.9 & 79 & 20.0 & $B N$ & 198 & 69 \\
\hline SSI & 9.3 & 14.0 & 73 & 20.0 & Mo & 220 & 58 \\
\hline SSI & $\begin{array}{l}\text { not } \\
\text { measured }\end{array}$ & 12.0 & 80 & 14.0 & BN & 199 & 57 \\
\hline SSL & 7.0 & 15.6 & 73 & 20.0 & Mo & 205 & 56 \\
\hline SSL & $\begin{array}{l}\text { not } \\
\text { measured }\end{array}$ & 14.0 & 79 & 14.5 & $\mathrm{BN}$ & 200 & 53 \\
\hline SIL & 6.4 & 12.5 & 84 & 9.0 & Mo & 202 & 52 \\
\hline SIL & 6.4 & 12.5 & 73 & 9.0 & $\mathrm{BN}$ & 200 & 51 \\
\hline SLL & 6.4 & 13.5 & 84 & 8.0 & Mo & 198 & 55 \\
\hline SLL & 6.4 & 14.0 & 84 & 7.0 & $\mathrm{BN}$ & 203 & 55 \\
\hline ILL & 4.5 & 15.5 & 80 & 9.5 & Mo & 200 & 61 \\
\hline ILL & 4.5 & 15.0 & 80 & 8.0 & BN & 199 & 58 \\
\hline LLL & 3.5 & 15.0 & 80 & 10.0 & Mo & 200 & 55 \\
\hline LLL & 3.5 & 14.0 & 80 & 8.5 & $\mathrm{BN}$ & 200 & 62 \\
\hline ISS & 5.1 & 9.0 & 83 & 20.0 & $\mathrm{BN}$ & 145 & 52 \\
\hline ILL & 4.1 & 14.0 & 77 & 9.0 & BN & 200 & 54 \\
\hline IIL & 4.7 & 14.0 & 73 & 13.0 & $B N$ & 202 & 52 \\
\hline LIL & 3.9 & 14.0 & 71 & 14.5 & $\mathrm{BN}$ & 202 & 54 \\
\hline
\end{tabular}

*See text for definition of S,I,L. 


\section{DESIGN: ILL}

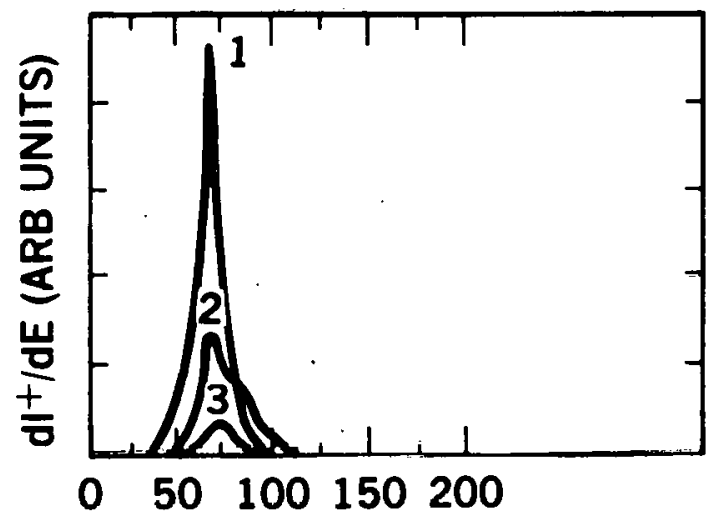

ION ENERGY (eV)

$$
\begin{array}{ccc}
P=4.1 \mathrm{~Pa} F=14.0 \mathrm{sccm} & \\
\mathrm{V}_{\mathrm{A}}=77 \mathrm{~V} & \mathrm{I}_{\mathrm{A}}=9 \mathrm{~A} & \mathrm{I}^{+}=200 \mathrm{~mA} \\
\mathrm{D}^{+}=54 \% & \mathrm{D}_{2}^{+}=41 \% & \mathrm{D}_{3}^{+}=5 \%
\end{array}
$$

DESIGN: IIL

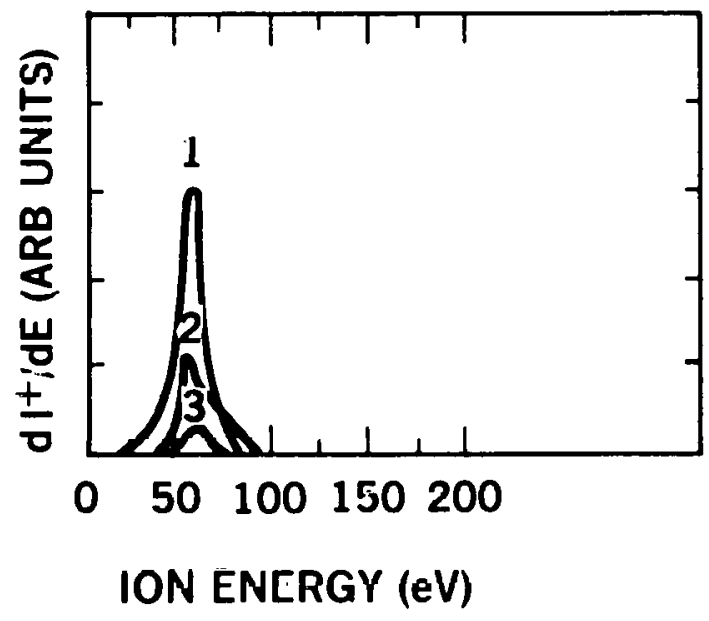

$$
\begin{array}{ccc}
P=4.7 \mathrm{~Pa} F=14.0 \mathrm{sccm} & \\
\mathrm{V}_{\mathrm{A}}=73 \mathrm{~V} & \mathrm{IA}_{\mathrm{A}}=13 \mathrm{~A} & \mathrm{I}^{+}=202 \mathrm{~mA} \\
\mathrm{D}^{+}=52 \% & \mathrm{D}_{2}^{+}=41 \% & \mathrm{D}_{3}^{+}=6 \%
\end{array}
$$

Fig. 10. Ion energy distributions relative to cathode potential (ground) for two duopigatron configurations. $P$ is source pressure, $F$ is feed gas flow rate, $V_{A}$ is arc voltage, $I_{A}$ is arc current and $I^{+}$the total ion current. 
An important requirement for any new source configuration was that the current density profiles remain as "flat" as the SSS version. That is the current density near the plasma expansion cup wall at the exit plane ( $z=0$ in Fig. 9) should be at least 80 percent of the center line density. For all of the designs tested this requirement was met and a summary of several of the designs is presented in Fig. 11 .

The configuration that appears the most satisfactory is the IIL with a BN secondary cathode. This efficient source produces a $200 \mathrm{~mA}$ ion beam at $13 \mathrm{~A}$ and has a flat current density profile. Experimental data for this configuration are shown in Fig. 12. This design distributes the secondary electron power among the anode, IE and a beam catcher attached to the filament support holder without damaging any of these electrodes. In addition, the IE aperture is sufficiently small to shield the filament from damage but at the same time is large enough not to intercept enough secondary electron power to be melted.

In order to determine the contaminant levels of the ion beam by heavy ionic species sources were tested in the new mass spectrometer test stand. The experimental arrangement is analagous to previous work, ${ }^{3}$ with the important exception that the quadrupole mass spectrometer has been moved closer to the ion source. 'The sensitivity of the analysis has been improved from 20 PPM to 5 PPM and isotopes of $\mathrm{Fe}$ and $\mathrm{Cu}$ are now resolvable. As of the writing of this report, complete testing has not been finished and the results presented should be regarded as preliminary.

The major source of very heavy impurities is the Fe expansion cup. Only trace amounts of $\mathrm{Fe}$ can be attributed to the IE. Also, at a fixed arc current the amount of heavy metal ions is a strong function of magentic field. For example, decreasing the magnetic current from its usual value of $2 A$ to $1 A$ reduced the $F e$ and $C u$ components from $0.009 \%$ and $0.004 \%$ to $0.002 \%$ and $0.0004 \%$ respectively. Some $\mathrm{Sr}^{++}$. from a newly dipped and activated oxide filament was initially observed but became undetected after a few hours of operation. The major source of contaminants remains (as also noted in Ref.3). The "best" results for the IIL source are reported in Table III.

Future duopigatron experiments will include obtaining the impurity ion spectrum for the source operation with dispenser cathodes as opposed to oxide coated filaments. Also, the alumina spacers will be replaced with ribbed alumina spacers or pyrex spacers to investigate the role of thesc types of surfaces on impurity production. (The pyrex spacers will also permit a qualitative optical spectra analyses.) In view of racently obtained focussing improvements using reduced magnet current (see Section II-C), the source characteristics will be measured as a function of magnetic field strength. 
DESIGN: SSS

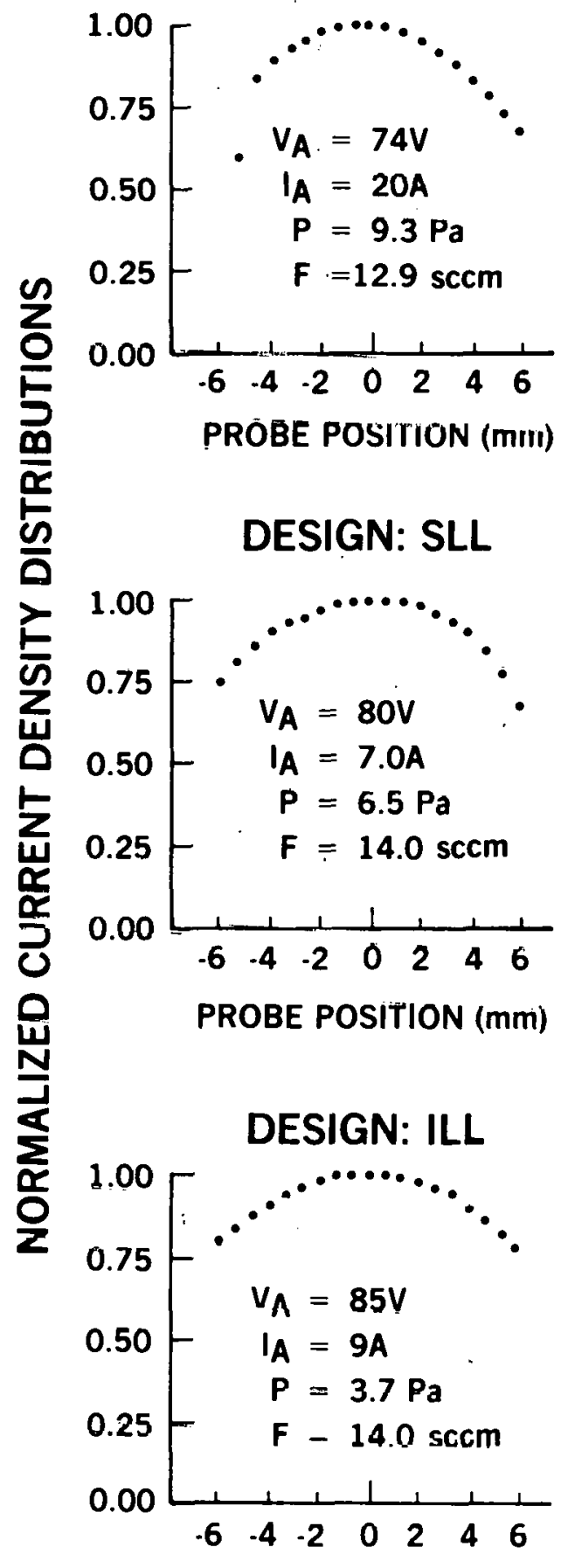

PROBE POSITION (mm)
DESIGN: SIL

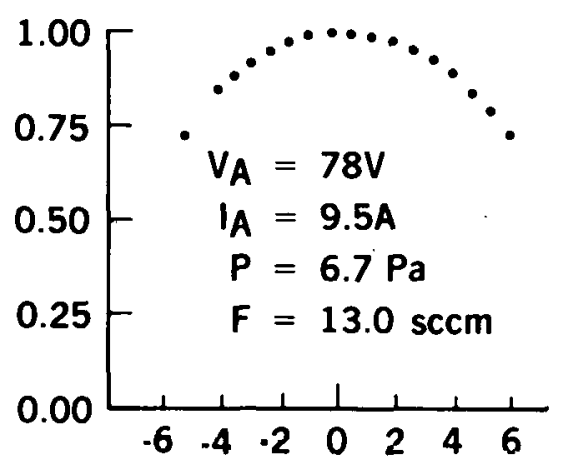

PROBE POSITION (mm)

DESIGN: LLL

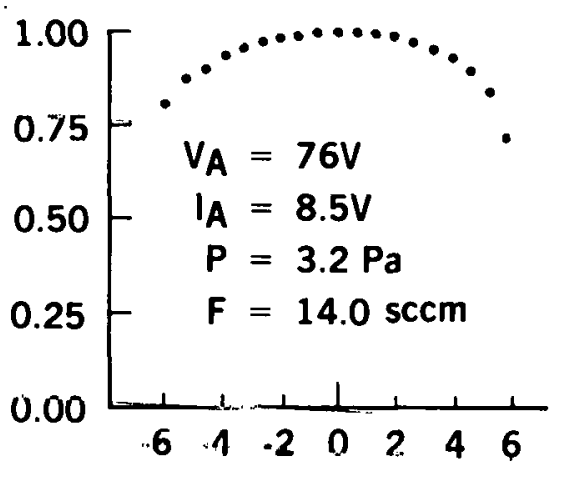

PROBE POSITION (mm)

DESIGN: IIL

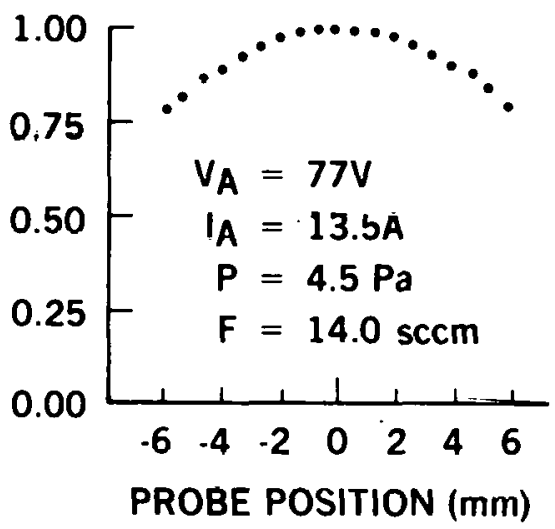

Fig. 11. Current density distributions in the exit plane $(z=0)$ of the plasma cup for several representative configurations tested. See Fig. 10 for nomenclature. 


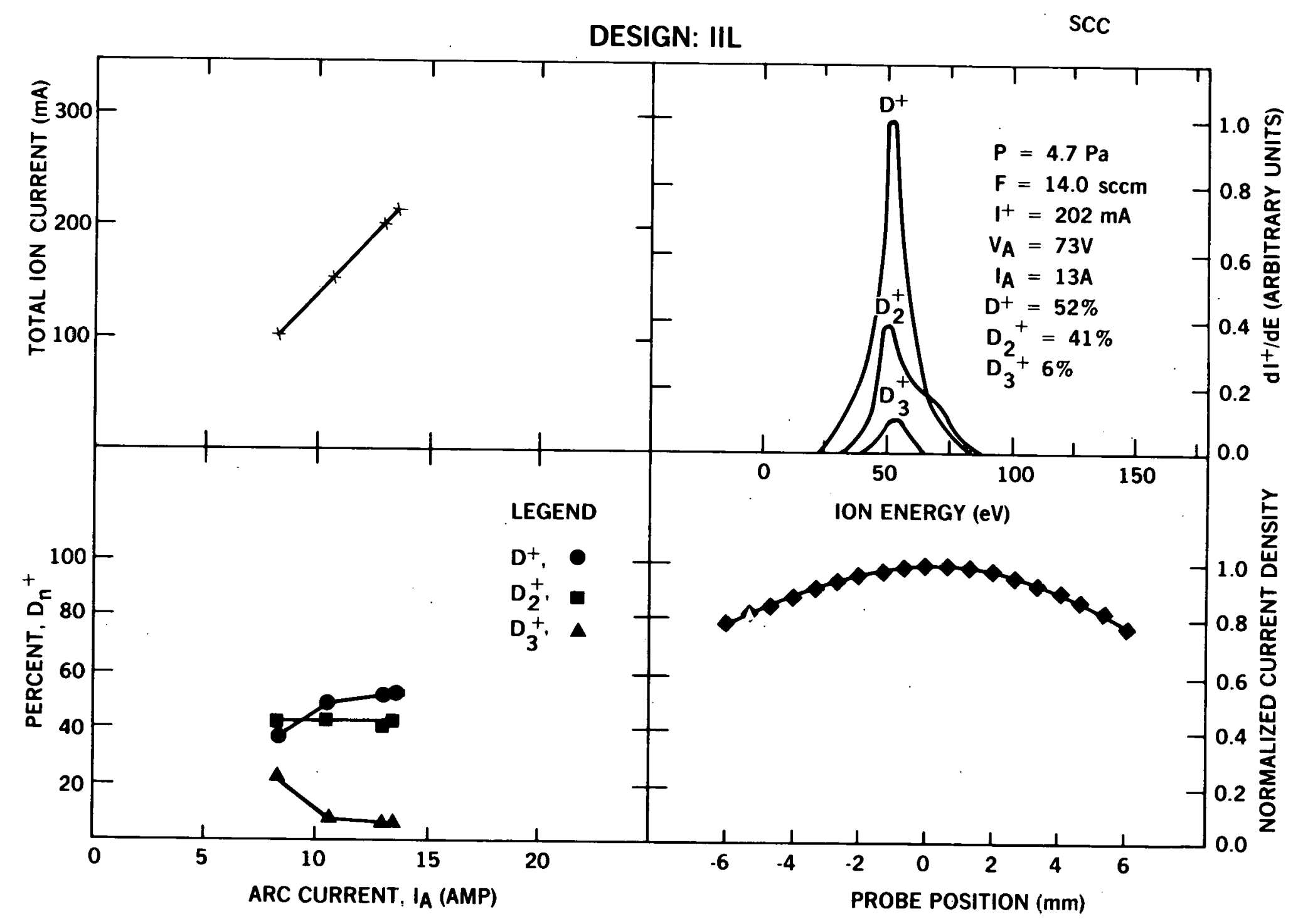

Fig. 12, Experimental data abtained on duopigatron design IIL. Upper left panel is total ion current ys arc current at $4.7 \mathrm{~Pa}$ source pressure. Lower right is the ion current density distributicn in $Z=0$ plane of piasma expansion cup for $13 \mathrm{~A}$ arc current and $4,7 \mathrm{~Pa}$ source pressure. 
Table III. Ion Beam Impurities on a Duopigatron Ion Source (a) After Several Hours of Operation

\begin{tabular}{lll}
\hline $\mathrm{m} / \mathrm{e}$ & \multicolumn{1}{c}{ Species } & Percent \\
\hline 11 & $\mathrm{~B}^{+}$ & 0.004 \\
$\mathrm{li}$ & $\mathrm{C}^{+}$ & 0.03 \\
14 & $\mathrm{CD}^{+}$ & 0.04 \\
16 & $\mathrm{O}^{+}, \mathrm{CD}_{2}^{+}$ & 0.17 \\
18 & $\mathrm{DO}^{+}, \mathrm{CD}_{3}^{+}$ & 0.16 \\
20 & $\mathrm{D}_{2} \mathrm{O}^{+}, \mathrm{CD}_{4}^{+}$ & 0.22 \\
22 & $\mathrm{D}_{3} \mathrm{O}^{+}, \mathrm{CD}_{5}^{+}$ & 0.03 \\
28 & $\mathrm{CO}^{+}, \mathrm{N}_{2}^{+}, \mathrm{Fe}^{++}$ & 0.004 \\
56 & $\mathrm{Fe}^{+}$ & 0.0016 \\
Contaminant Total & $=0.7 \%$ &
\end{tabular}

(d) Source conflyuration IIL with a BN Secondary iachode. 


\section{B. Cusp Field Source}

Cusp field gas discharge ion sources ${ }^{12}$ are of particular interest for use in the TTF. These sources are noted for stable operation, flat current density profiles and much lower operating pressures. The low operating pressure presents the intriguing possibility of incorporating this type of source into an unpumped facility.

Preliminary experiments will investigate two cusp designs. The first will be a modification of the Berkeley mutlifilament source that was tested in our laboratory. 11 The modification is the addition of radial magnets located around the surfaces designated floating electrodes in Ref. 11. Careful attention will be paid to the effect of the addition of the cusp fields on the percent of $D^{+}$in the ion beam. Previously, this source produced unsatisfactorily low levels of $D^{+}$.

The second source to be tested (see Fig. 13) is based on the Los Alamos configuration. ${ }^{13}$ This source consists of a $32 \mathrm{~mm}$ stainless steel cube surrounded on 5 sides by ceramic magnets inserted in water cooled copper blocks. The plasma will be analyzed using hot wire probes inserted directly into the cube and at the exit aperture. Experiments will be designed to maximize $D^{+}$content and minimize source operating pressure.

\section{ULTRA-HIGH VACUUM NEUTRON TUBE DESIGN}

An ultra high vacuum version of the cancer therapy neutron tube has been designed and the required components are being fabricated. A schematic diagram of the ion source and accelerator sections of the tube is shown in Fig. 14. The ion source is an ultra high vacuum version of a duopigatron. The accelerator consists of a single stage $20 \mathrm{~mm}$ accelerator gap. The critical components shown are the focus electrode, extractor electrode, and neutralizing electrode. Figure 15 shows what the experimental UHV closed cycle generator will look like.

\section{A. Ion Source}

The ultra high vacuum ion source is completely enclosed in an aluminum coolant bucket through which chilled fluorinert will be circulated to dissipate the excess ion source heat. At the top of the ion source is a combination filament holder and beam catcher, consisting of a copper block brazed into a $85.7 \mathrm{~mm}$ ultra high vacuum flange. As in the beam catcher mentioned in an earlier section of this report, a tapered coaxial hole is drilled into the copper block to dissipate the energy of the secondary electrons generated in the accelerator section of the tube. The copper block also holds the bakeable ceramic filament feedthroughs. 


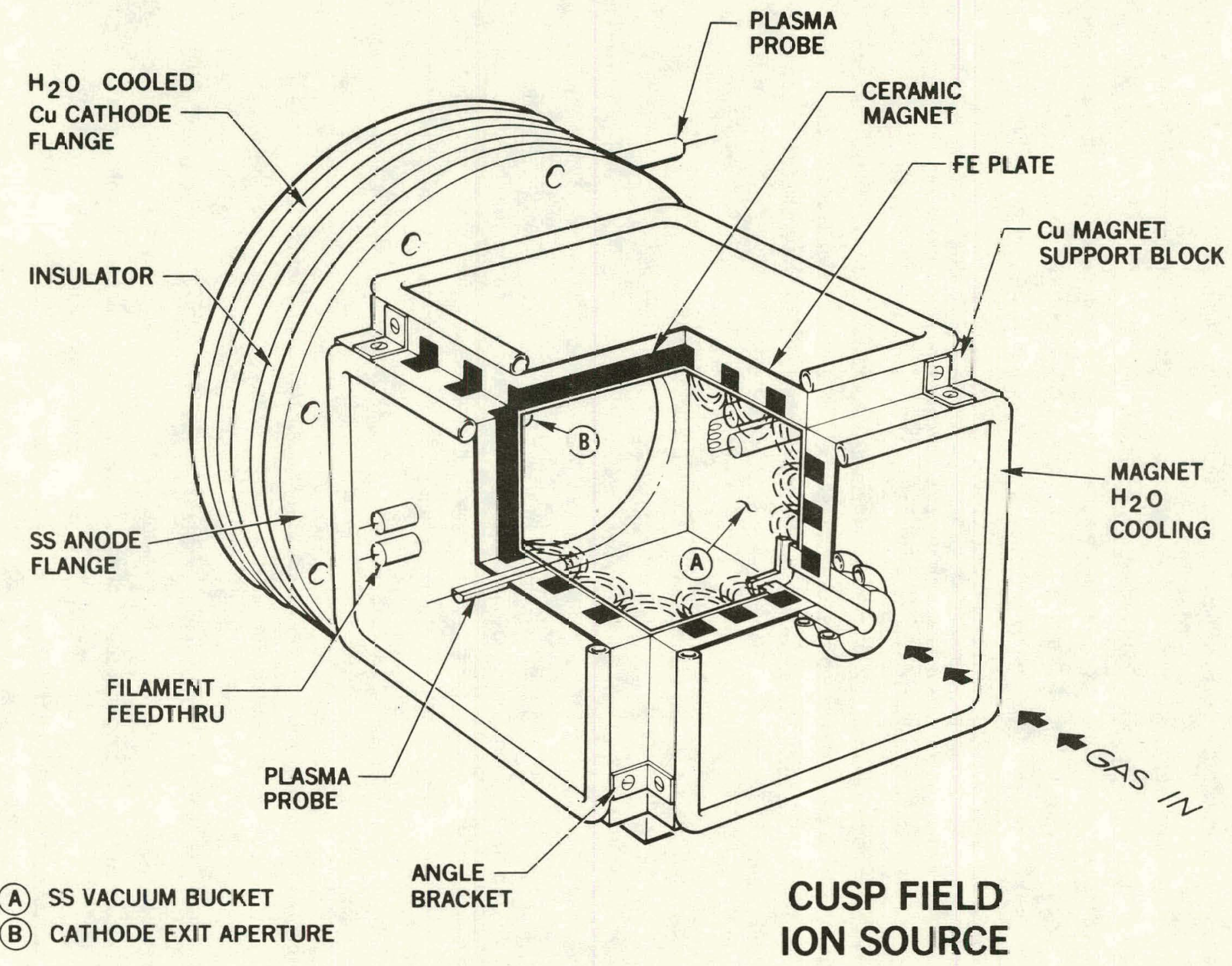

$10 \mathrm{~cm}$

Fig. 1ミ. Schematic drawing of the cusp field ion source. 


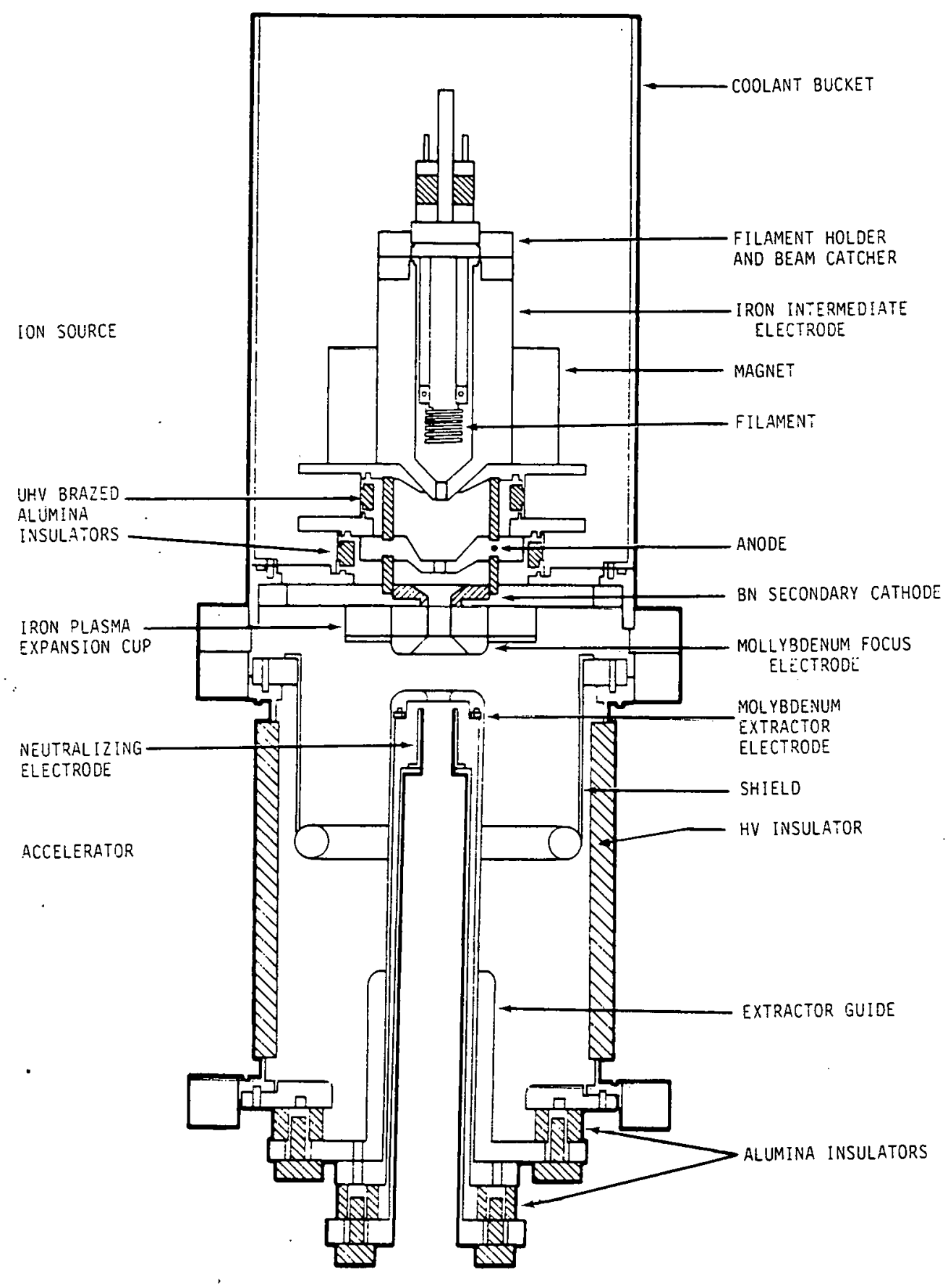

Fig. 14. An assembly drawing of the ion source and accelerator sections of the ultra-high vacuum version of the neutruil tube. 


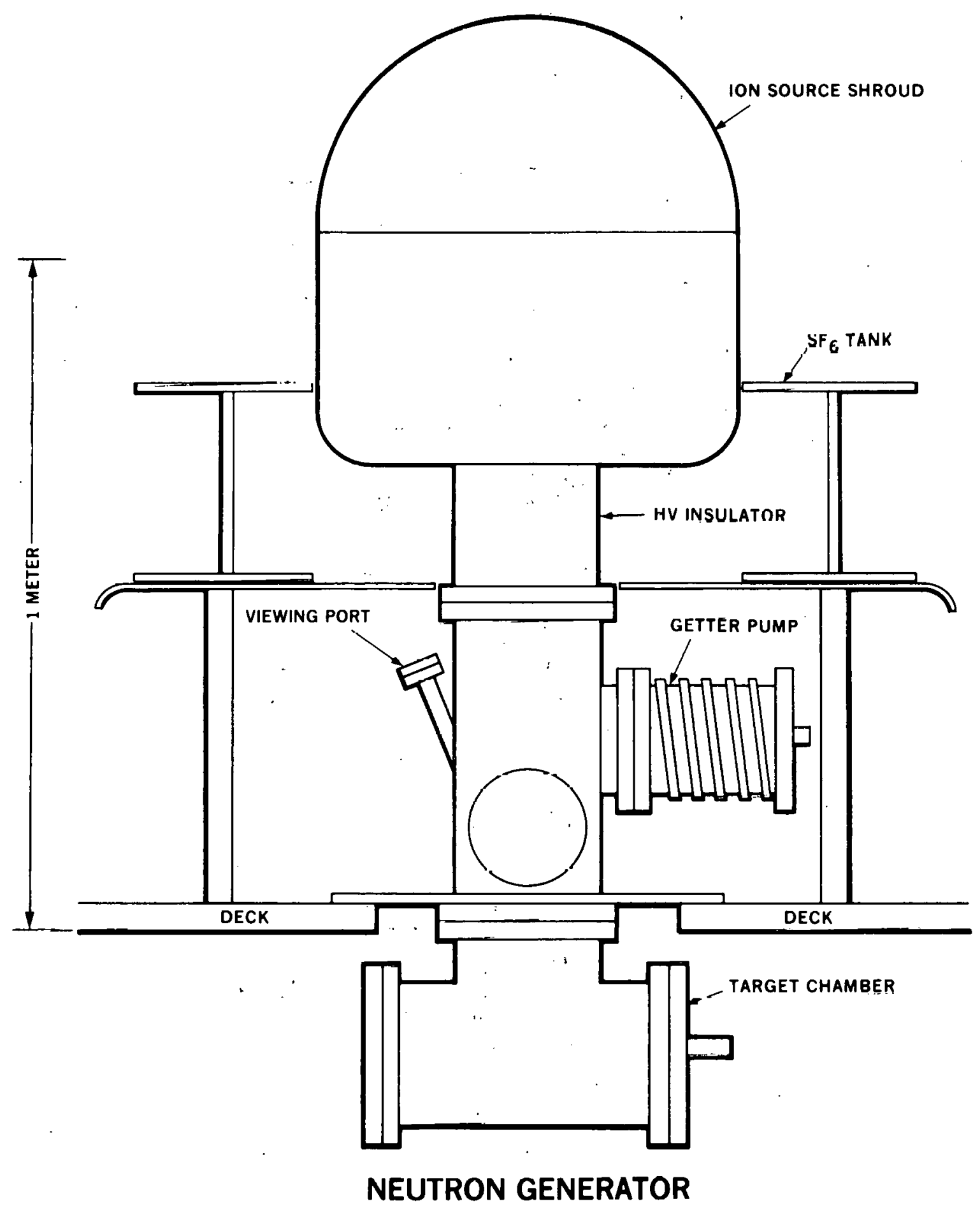

Fig. 15. Schematic layout of the fully assembled UHV neutron tube. 
An important part of the ion source is the iron intermediate electrode, which is shown brazed to a copper coolant plate. A $85.7 \mathrm{~mm}$ flange is brazed to the top of the intermediate electrode to mate with the filament holder flange. The required electro-magnet coil was designed to fit over and around the intermediate electrode. The current design calls for the gas feed line to be brought through the intermediate electrode below the magnet coil. This was done to facilitate coil removal for the necessary $450^{\circ} \mathrm{C}$ bakeout.

Within the intermediate electrode is the filament. It is presently anticipated that the dispenser type cathode, a commercially available BaO impregnated tungsten filament, will be used. Several designs are being considered. One will use a single large filament as shown in Fig. 14. An alternative design will use several small cathodes arranged symmetrically around the axis. Since the exact lifetime of the filament is not yet known, the latter design could provide an added degree of reliability by providing additional filaments in situ in the event of a failure.

Next is the anode. At present, it is made of copper, and is cooled by physical contact with a copper plate immersed in the fluorinert coolant. The anode is removable to provide some flexability in the design configuration. The design requires that the anode be capable of absorbing and dissipating some of the energy from the secondary electron beam.

Below the BN secondary cathode is an iron plasma expansion cup. A molybdenum focus electrode is screwed to the iron expansion cup which is attached to a cooled copper support plate.

The entire ion source is brazed together using ultra high vacuum brazing techniques with alumina insulators to provide electrode separation. The insulators are not directly exposed to the arc plasma. Instead, removable insulators, as shown in Fig. 14, are located within the brazed insulators and are physically trapped between the intermediate electrode and the anode, and between the anode and secondary cathode respectively. This demountable feature permits cleaning or replacement with other types of insulator materials.

At the present time, the aperture configuration of the ion source calls for a $9.5 \mathrm{~mm}$ aperture in the intermediate electrode, a $9.5 \mathrm{~mm}$ aperture in the anode, and a $12.7 \mathrm{~mm}$ aperture in the $\mathrm{BN}$ seccondary cathode and plasma expansinn cup. It has been found that this configuration provides a good focus capability and an efficient ion source operation. An alternative to the molybdenum focus electrode shown has been designed by J. E. Boers, using a computer code SNOW, ${ }^{9}$ which appears to give a better focusing characteristic than the one shown. It is anticipated that focus electrode will be used. 
The entire ion source assembly is brazed into a $254 \mathrm{~mm}$ diameter stainless steel conflat flange to provide a UHV seal to the accelerator section.

\section{B. Accelerator}

The accelerator section of the neutron tube consists of a single $20 \mathrm{~mm}$ acceleration gap between the field shaping electrodes separated by the high voltage insulator. At the top of the accelerator, a shield electrode is fastened which prevents secondary electron damage to the high voltage insulator itself. It may also prevent or limit $x$-ray damage or x-ray initiation of insulator flashover type breakdowns.

Within the shipld, the extractor clectrati, runststing of a molybdenum cap having a $12.7 \mathrm{~mm}$ aperture, is attached to a stainless steel tube. Within the extractor electrode is a neutralizing electrode, designed to le cenlered under the extractor cap, which provides the necessary retarding potential for electrons generated by the ion beam. The electrons, thus trapped below the extractor, effectively neutralize the space charge of the ion beam thereby limiting the beam divergence. The extractor electrode tube is inserted into the extractor quide, whir:h in turn in mounted on alumina ceramic insulator separating it from the base of the accelerator. The guide is designed to be positioned on the insulators to provide concentric alignment with the ion source. In a similiar manner, the neutralizing electrode tube is mounted and separated from the extractor electrode by alumina insulators which allow the same freedom of positioning for concentricity. Because of the design of the extractor and neutralizing clcctrode supports, the gap can be easily adjusted by placing spocer's belween the base of the extractor electrode and the extractor quide. With these factors, this design should provide a maximum degrep of flexibility for determilly the optimum accelerator configuration.

The liigh vultage insulator is a $200 \mathrm{~mm}$ diameter Re- $X$ glass ceramic. At the present time it is not segmented. However, if surface flasliuver are found to be $a$ significant problem, a seqmented versinn described in Scction $V$ will be invcstigated. Figure 15 shows a complete schematic of the proposed neutron generat.nrs. The ion bcam will be transported $0.9 \mathrm{~m}$ from the accelerator gap to the target. The ion source will be enclosed in a dome shaped ion source shroud to limil lhe effects of corona, and the high voltage insulator will be nnclosed in a plexiglass $S F_{6}$ tänk to prevent external IIVD's. A urift chamber below the accelerator section will contain the necessary instrumentation and pumping apparatus. Getter pumps manufactured by Westinghouse or SAES will be used to act as both pumps and reservoirs for the deuterium gas. The target chamber w111 consist of a commercial $254 \mathrm{~mm}$ tee adapted for the target experiments. Initial tests will be made using the sandwich target design described previousiy. ${ }^{1,2}$ 0ther target designs will be considered, including a moveable target and special contoured targets for increased target lifetime. The entire neutron tube will be bakeable at $450^{\circ} \mathrm{C}$ to provide the required ultra high vacuum conditions. 
A suitable closed cycle gas supply system for the ion source is currently being investigated. Since the duopigatron ion source requires a continious gas flow of $\sim 20 \mathrm{STPCC} / \mathrm{m}$, it may be necessary to locate the gas reservoir and gas flow controllers within the ion source shroud. This may complicate the control circuitry since they will then be at high voltage. On the other hand, if the gas supply and control system can be placed at ground potential, they could be easily controlled. However, the latter design requires a special alumina gasline designed to hold off the $200 \mathrm{kV}$ operating voltage with internal gas pressures as high as $70 \mathrm{~m}$ Torr. A mock-up of this design will be tested shortly. If this gas supply cannot be handled from ground potential, the former design will be pursued.

\section{SEGMENTED HIGH VOLTAGE INSULATOR}

A $350 \mathrm{~mm}$ diameter segmented insulator may be necessary to achieve the high voltage reliability needed for hospital operation of a neutron tube. Surface flashover of the straight-wall, $200 \mathrm{~mm}$ diameter insulator that is now being used has been a problem. The larger, segmented insulator will be an improvement because the fields are more uniformly graded along the insulator wall and, with the larger diameter, the fields can be shaped so that the probability of surface flashover is reduced. A program to build a glass-ceramic insulator is now underway in the glass-ceramic shop. Stress calculations indicate that the residual stresses due to manufacturing the present design should not cause cracking of the glass-ceramic. Molds for the insulator are now being designed. The first insulator build should be completed this summer.

\section{TARGET PHYSICS STUDIES AT $40 \mathrm{keV}$}

Operation of the intense neutron source target in a dynamic equilibrium mode necessitates that the hydride film be maintained within certain temperature limits. ${ }^{14}$ These limits are dependent on the ion beam energy and composition, the current density on the target, and the composition of the target film. Under this mode of operation (1) the film is hypothesized to remain stable in the dihydride phase and (2) beam implanted hydrogen isotopes are expected to be released from the film at the implant rate. These conditions in turn depend on characteristics of the hydride film under high current density ion bombardment: namely, upon (1) the high temperature hydride dissociation limits and (2) the hydrogen isotope mobilities. These characteristics along with the effects of surface oxidation and beam implanted impurities are the subject of investigations on a $40 / \mathrm{keV}$ Target Physics Accelerator (TPA) ${ }^{5}$

Although the gross thermal dissociation prediction of the dynamic equilibrium model has been verified for scandium films under low current density bombardment, ${ }^{15}$ the subtle current density dependence of this dissociation has not heen observed. During 
the past year several attempts have been made at observing this effect using a thermal ramping technique. These attempts have not been successful due to difficulties in producing a thermal ramp which is reproducible under varying bombardment conditions. An alternative approach, using the sensitivity of dynamic deuterium pressure analysis rather than target yield, is under investigation.

The bulk of the work on the TPA during the past year has been aimed at measuring the deuterium diffusion. Typically, diffusion measurements have been made on bulk samples, in which grain size can play an important role. There is little information about diffusion in granular films, particularly those of interest for neutron snurce targets. Permeation and outgassing measurements are frequently dominated hy surface effect.s and heam-enhanced mobilitipe in targete arc only hypothesized. $A$ theory hảs been developed wherein the effective diffusion normal to the surface can be measured in both the ion-danacyed and unpenetrated regions of a film by merely observing the temporal development of the near-surface deuterium concentration. The technique is not sensitive to artifical surface permeation barriers and provides data near the temperature range of interest. The TPA system is ideally suited to these measurements in terms of instrumentation for dynamic near-surface concentration measurement and outgassing sensitivity. A specially designed sample holder has been added for these measurenents to improve target temperature control during bombardment transients. other recent modifications include improvements to beam collimation, current measurement, and data multiplexing. A second ion lens has been added which increases the obtainable current density to $2 \mathrm{~mA} / \mathrm{cm}^{2}$.

A typical diffusion measurement is shown in Fig. 16. Here, the average deutieriullto-scandium ratio in the near-surface area is plotted $(+)$ as a function of time, starting with a fully-outgassed, $0.515 \mu \mathrm{m}$ thick film. This ratio was deduced froll the $40 \mathrm{keV} D(d, p) T$ yield using the titanium calculations of Shope. ${ }^{16}$ The target temperature was maintained at $12 \pm 1^{\circ} \mathrm{C}$, while deuterion bombarded with a current density of $0.48 \mathrm{~mA} / \mathrm{cm}^{2}$. No implanted deuterium escaped the target during this measurement, as indicated by deuterium partial pressure analysis in the target chamber.

The solid curves in Fig. 16 show the temporal development of this D/SC ratio predicted from a solution to the one-dimensional diffusion equation with a source term and impermeable boundaries. The only adjustable parameter in this solution is the diffusion coefficient, $D$. Clearly, the first part of the data is accurately fit using $D=3 \times 10^{-12} \mathrm{~cm}^{2} / \mathrm{s}$. However, when the concentration reaches $\mathrm{D} / \mathrm{SC} \approx 0.3$, a sharp deviation occurs. This is believed to be due to the creation of the hydride phase near the deuteron's end-of-range. Continued bombardment causes the phase front to proceed toward the surface region, increasing the average $\mathrm{O} / \mathrm{SC}$ ratio. The modeling of this behavior is under development. The measurement shown in Fig. 16 is thus for the solid solution $(\alpha)$ phase rather than the hydride phase. The latter can be investigated by preloading the target film with protium. These studies are in progress. 


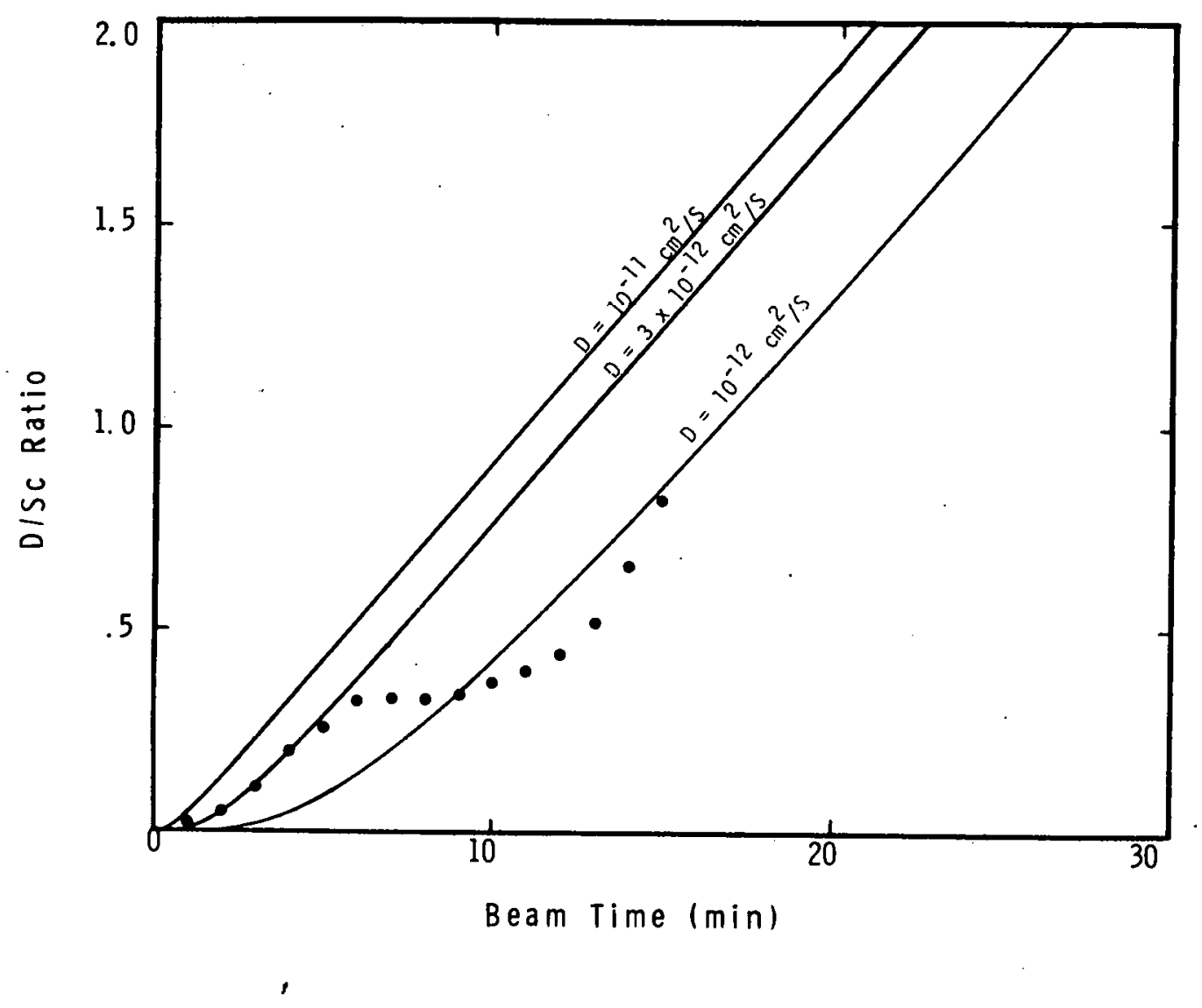

Fig 16. Near-surface deuterium concentration deduced from the $D(d, p) T$ yield at $40 \mathrm{keV}$, as a function of beam time. For short times, this concentration fits the diffusion model (solid curves) with $D=3 \times 10^{-12} \mathrm{~cm}^{2} / \mathrm{s}$. Subsequent deviation from the model is discussed in the text. 
Measured diffusion coefficients for the $\alpha$-phase as a function of temperature are plotted in Fig. 17. Also shown, by the solid line, are the results of Weaver's measurements in bulk, powdered scandium. ${ }^{17}$ The $f i l m$ and bulk data agree for temperatures above about $150^{\circ} \mathrm{C}$. Below this, however, diffusivities in the film can be substantialiy greater than in the bulk. Experiments are underway to determine whether this difference is due to inherent film structure effects or ion damage enhancement.

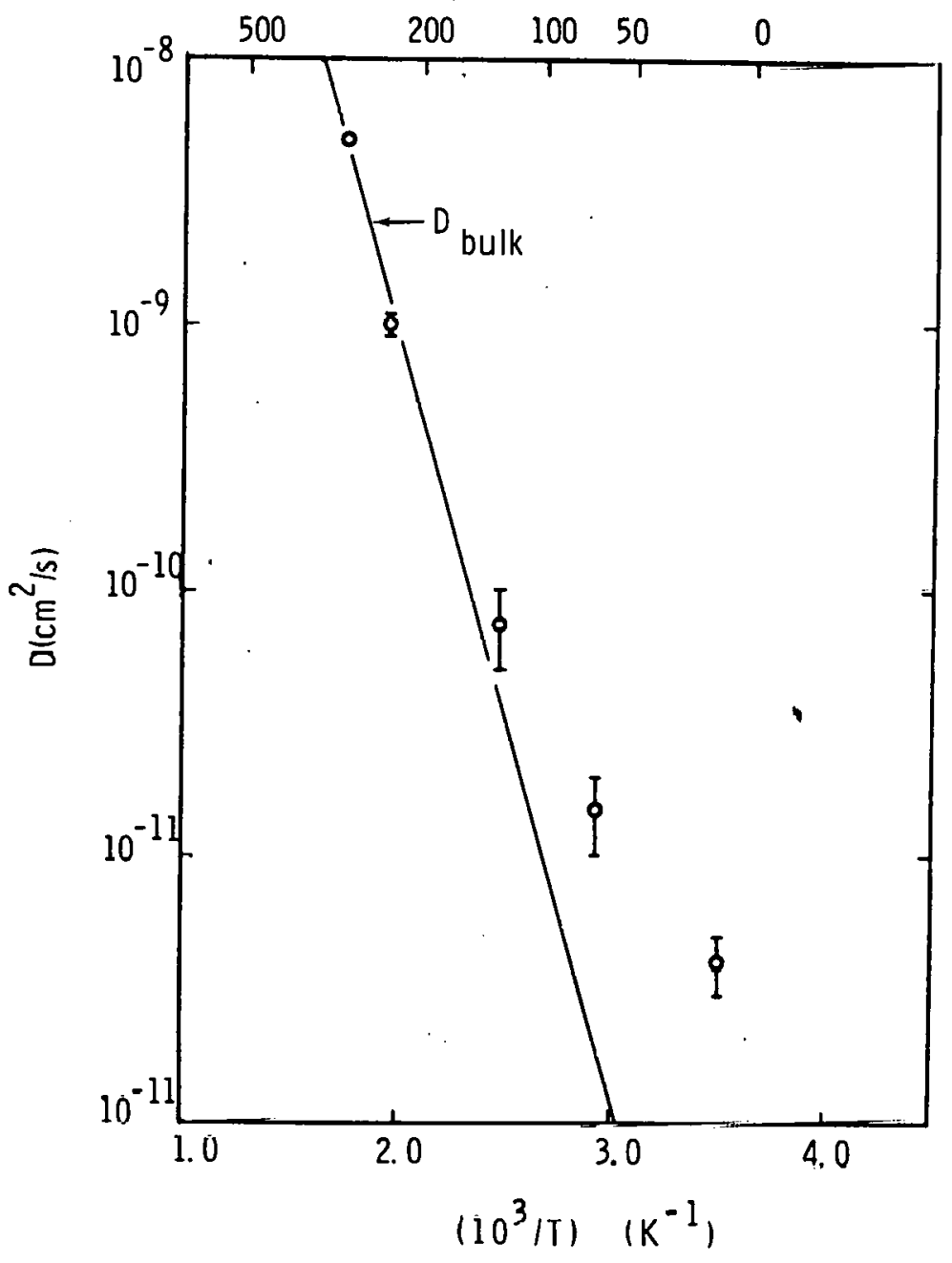

Fig. 17. Measured deuterium diffusitivity in $\alpha$-phase scandium films as a function of temperature. Deviation from the bulk Arrhenius behavior of Weaver ${ }^{6}$ occurs for temperatures below $150^{\circ} \mathrm{C}$. 


\section{SUMMARY OF FUTURE PLANS}

Testing the ultra-high vacuum (UHV) neutron tube for neutron output, target lifetime and high voltage reliability should commence in June, 1980. Initial tests will begin using the UHV accelerator attached to the target chamber (lower chamber in Fig. 1) so that dynamic deuterium concentration depth profiles measurements can be made. Following these tests, the target chamber in Fig. 15 will replace the target test chamber for further testing. Special target designs will be tested using this facility.

In parallel with the UHV tube tests, the multi-cusp magnetic field ion source will be evaluated for low pressure operation. As the operating and geometrical parameters of this source are better defined, a UHV model of the source will be designed and constructed for test on the UHV tube. The $350 \mathrm{~mm}$ diameter segmented insulator is scheduled for completion later this summer; when available, it will be evaluated on the UHV tube. By the end of the grant period, (June 1, 1981) a Mod II UHV tube should have evolved that will incorporate any improvements identified in the above tests. This tube should be designed with the idea of packaging it in a container that would eventually be operated inside a rotable neutron shield/collimator.

Experiments applicable to the intense neutron source will be continued on the $40 \mathrm{kV}$ accelerator to determine the diffusion parameters of deuterium and impurities in the target film. Models of the behavior are presently being developed. 


\section{References}

1. F, M. Bacon, D. F. Cowgill, R. W. Bickes, Jr. and A. A. Riedel, "Intense Neutron Source Target Test Facility: Fourth Semi-Annual Progress Report," Sandia Labs. Report SAND78-2323, January, 1979.

2. F. M. Bacon and A.A. Riedel, IEEE Trans. Nucl. Sci. NS-26, 1505 (1979)

3. R. W. Bickes, Jr. and J. B. O'Hagan, J. Appl. Phys. 50, 3247 (1979)

4. F. M. Bacon and A. A. Riedel, "Development Program for Cancer Therapy Neutron Source," Sandia Labs. Report SAND79-1272, June 1979.

5. D. F. COWg111, ILEE Trans. NuCl. Sci. NS-26, 1697 (1979)

G. F. M. Bdcun, K. W. Bickes, Jr. and J. B. Q'Hagan, Rev Srị. Instrum. 49, 4J5 (1978)

7. E. W. McDaniel, Collision Phenomena in Ionized Gases pp. 282-283 (John Wiley, New York, 1964)

8. D. F. Cowgill, "Dynamic Implant Profiling by Low-Energy Nuclear Reaction Spectroscopy," Nucl. Instrum. and Methods 145, 507 (1977)

9. J. E. Boers, "SNOW - A Digital Computer Program for the Simulation of Ion Beam Devices," Sandia Labs. Report SAND79-1027, to be published.

10. F. M. Bacon, Rev. Sci. Instrum. 49,427 (1978).

11. R. W. Bickes, Jr., F. M. Bacon and J. B. O'Hagan, Rev. Sci. Instruin. 49, 1513 (1978).

12. R. Limiateller and K. K. Mackenzie, Rev. Sci. Inștrum. 44. 726 (1973).

13. J. D. Schneider, Private Communication (1980),

14. D. F. Cuwy 111 , "Diftusivity Probing in Ion-Implanted Targets with the ${ }^{2} H(d, n)^{3} \mathrm{He}$ Reaction," SAND75-5354A, 11 th Annual Symposium of the NM Chapter of the AVS, Albuquerque, NM, May 6-8, 1975.

15. F. M. Bacon, A. A. Riedel, C. F. Cowgill, J. E. Boers and R. W. Bickes, Jr., "Intense Neutron Source Target Test Facility: Third Semi-Annual Progress Report" Sandia Labs. Report \$AND78-ก370, February, 1978.

16. L. A. Shope, "Thenretical Thick Targct Yields for the D-D, D-T, and T-D Nuclear Reactions Using the Metal Occluders Ti and Er and Energies up to $300 \mathrm{keV}, "$ Sandia Laborator:es Technical Memorandum SC-TM-66-247, (.luly 1966).

17. H. T Weaver. "Nuclcar Resomance Sludy of llydrogen Mulion in Metal Hydrides," Sandia Laboratories Technical Memorandum SC-TM-77-0889, (June 1973). 


\section{Distribution}

Francis J. Mahoney (5)

Dept. of HEW

Public Health Service

NCI Landow Building, Rm. C 809

Bethesda, MD 20074

LASL Ralph Stevens, MP-12

LASL John McConne 11, MP-12

LASL Robert Ham, AT-1

LASL PauT Allison, AT-1

LASL Joe Sherman, AT-1

LASL Dave Schneider, AT-1

2300 J. C. King

2350 J. T. Grissom

2352 F. M. Bacon (10)

2352 F. M. Bacon (25) for further distribution

2352 R. W. Bickes, Jr.

2352 D. F. Cowgill

2352 R. J. Walko

2352 J. B. O'Hagan

2352 A. A. Riedel

2353 J. T. Grissom, actg.

2354 B. E. Barnaby

2500 J. C. Crawford

2533 J. K. S. Walter, Jr.

2534 R. W. Roberts, Attn: J. Marcon

4231 S. A. Dupree

3141 Central Technical Library (5)

3151 W. L. Garner (3) for DOE/TIC

3154-3 R. P. Campbell (25) for DOE/TIC 


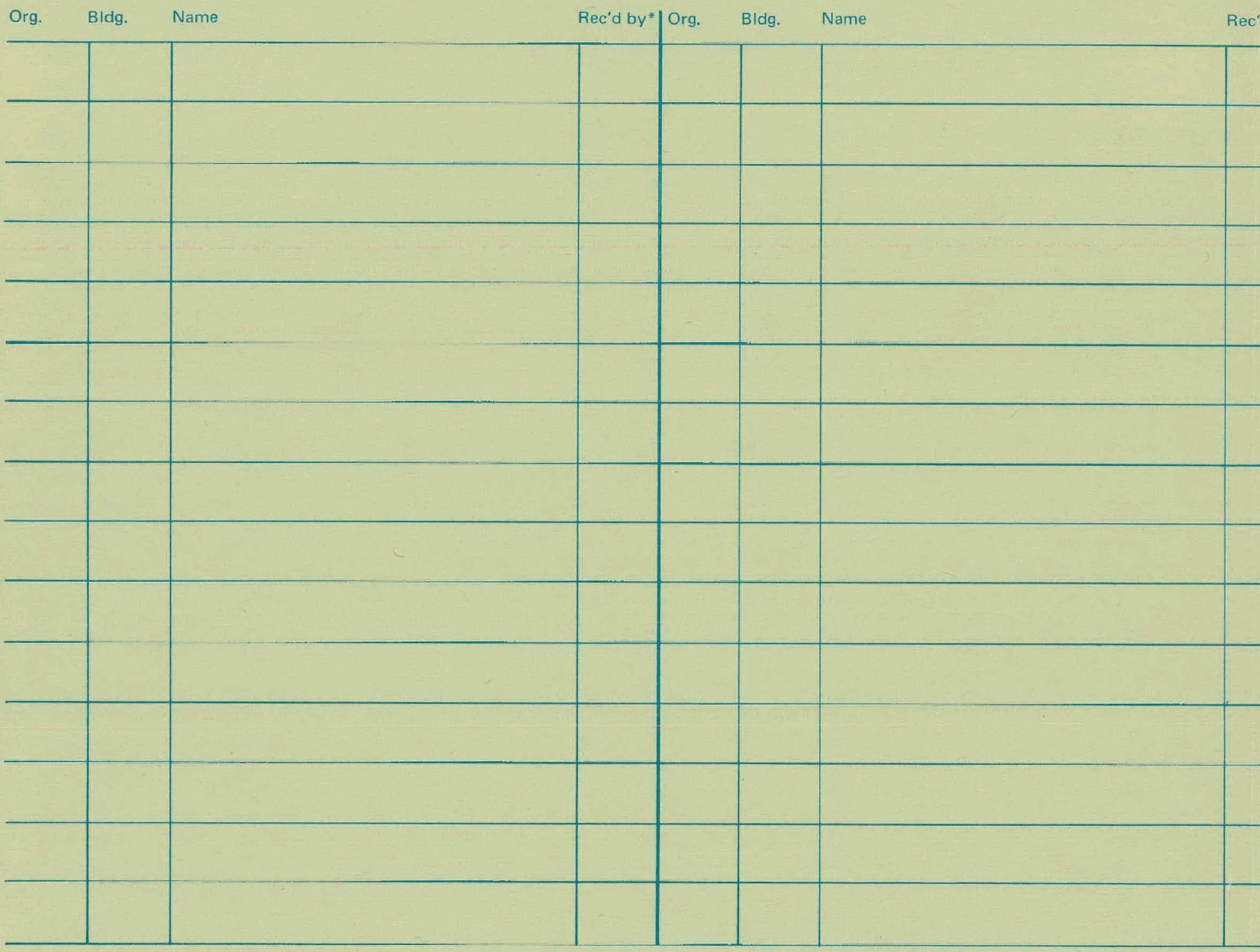

* Recipient must initial on classified documents. 